\title{
HACIA UNA CARACTERIZACIÓN DE UNA DISCIPLINA LINGÜÍSTICA (CASI) OLVIDADA: LA ETNOLINGÜÍSTICA*
}

\author{
José Carlos Martín Camacho \\ Universidad de Extremadura \\ jcmarcam@unex.es
}

TOWARDS A CHARACTERIZATION OF AN (ALMOST)

IGNORED LINGUISTIC DISCIPLINE: ETHNOLINGUISTICS

Recibido: $19 / 06 / / 2015$

Aceptado: 09/05/2016

\section{Resumen}

La etnolingüística es una disciplina casi olvidada, tanto en los manuales de lingüística como en la docencia y en la investigación sobre el lenguaje. En este estudio se combina la reflexión teórica sobre varias fuentes bibliográficas con el análisis de diversos hechos lingüísticos para intentar mostrar una propuesta de caracterización de esta disciplina, a la que se define como la encargada de estudiar el influjo que la cultura ejerce sobre el lenguaje, sea a nivel del sistema o sea en su uso efectivo en la comunicación. Esta definición se completa por dos vías. Primera, ubicando la etnolingüística dentro del panorama de la lingüística general, para lo cual se la distingue de la sociolingüística y, sobre todo, de la antropología lingüstica. Segunda, mostrando los ámbitos en que se manifiesta la relación de la cultura con el lenguaje y haciendo un repaso, no exhaustivo, de los diversos temas que puede estudiar esta disciplina.

PALABRAS CLAVE: Etnolingüística, Antropología Lingüística, Lenguaje y Cultura, Lingüística Externa.

\begin{abstract}
Ethnolinguistics is an ignored linguistic discipline, both in manuals and in language research. In this study, the theoretical reflection on literature sources, combined with the analysis of various linguistic facts, try to show a characterization of this discipline, which is defined as the discipline interested in studying the influence that culture has on language (in the system and in his use in communication). This definition is completed in two ways. First, placing ethnolinguistics within the panorama of general linguistics; for that, it is diferenciated from sociolinguistics and from linguistic anthropology. Second, showing the areas in which the relationship between culture and language is manifested and reviewing the various issues that this discipline can study. KEYWORDS: Ethnolinguistics, Linguistic Anthropology, Language and Culture, External Linguistics.
\end{abstract}

* Este trabajo se inscribe dentro del proyecto de investigación "Modelos y representaciones metateóricas en la historia de la Lingüística", financiado por el Ministerio de Economía y Competitividad (referencia FFI2012-35802)

Para citar este artículo / To cite this article: Martín Camacho, José Carlos (2016). Hacia una caracterización de una disciplina lingüística (casi) olvidada: la Etnolingüística. ELUA, 30: 181-212. doi:10.14198/ELUA2016.30.09

Enlace / Link: http://dx.doi.org/10.14198/ELUA2016.30.09 


\section{Introducción}

Como es bien sabido, la lingüística actual suele considerar que sus investigaciones deben parcelarse según la dimensión del lenguaje que constituya el foco de su interés, algo que permite distinguir diversas disciplinas científicas en función de cuál sea la faceta del lenguaje analizada (vid. por ejemplo Lyons, 1984: 29-31; Martín Vide, 1996: 11-17; Fernández Pérez, 1999: 32-42), ya sea en su vertiente de sistema de signos empleado para la comunicación (lo que suele denominarse "lingüística interna"), ya sea en el ámbito de las relaciones de ese sistema con los diferentes aspectos de la vida humana con los que confluye (la llamada "lingüística externa").

De ese modo, mientras que a la lingüística interna se adscriben la fonología y la fonética, la morfología o la sintaxis, en el campo de la externa se han definido y desarrollado disciplinas que estudian, entre otras, las relaciones del lenguaje con la sociedad, con la biología del ser humano y, para lo que aquí interesa, con la cultura.

Para estudiar esa relación, innegable, que existe entre el lenguaje y la cultura, se han propuesto diversas disciplinas: antropología lingüística, etnografía de la comunicación, etnosemántica, etnolingüística... De todas ellas, es la última de las citadas la que menos atención ha recibido, tanto en sí misma como en lo que respecta a su lugar dentro de la estructura de la propia lingüística.

En ese sentido, este estudio pretende indagar en las posibles vías para alcanzar una definición y una caracterización global de esta disciplina que permita ubicarla en el ámbito de la lingüística (en el sentido amplio que se ha asumido de lingüística como estudio del lenguaje en todas sus vertientes o "conjunto de las ciencias del lenguaje") y, a partir de ello, atribuirle un campo de trabajo unitario y delimitado, algo de lo que carece por varios motivos interrelacionados (cfr. Černý, 1998: 422-423): primero, porque sus temas de estudio se encuentran dispersos y repartidos entre otras disciplinas (antropología, etnografía, sociología, semántica, filosofía del lenguaje...); segundo, porque sus límites respecto de esas otras disciplinas, en especial de la sociolingüística y de la antropología lingüística (con la que de hecho se la identifica muy a menudo), no se han establecido con el rigor necesario ${ }^{1}$. A ello hay que unir que la etnolingüística puede considerarse el "pariente pobre" de otras ciencias del lenguaje $\mathrm{e}^{2}$, en especial de la sociolingüística, pues su desarrollo ha sido casi insignificante en comparación con el que ha tenido el estudio de la dimensión sociológica de las lenguas.

Para alcanzar ese objetivo, se partirá de las propuestas de definición que se han formulado de esta disciplina, en especial de aquellas que han intentado darle un marco teóricoconceptual propio y diferenciado de la antropología lingüística ${ }^{3}$. A ello se añadirán las

1 Eugenio Coseriu intentó, en un artículo programático al que haremos diversas alusiones en este estudio (Coseriu, 1981), distinguir la etnolingüística de esas otras dos disciplinas, pero su propuesta no parece haber tenido mucha repercusión en la lingüística contemporánea (cfr. nota 3).

2 Fernández y Hachén (1995: 2) llegan a considerar a la etnolingüística la "cenicienta" de las ciencias del lenguaje.

3 Los intentos de definir la etnolingüística como algo distinto de la antropología lingüística se reducen, posiblemente, al artículo de Coseriu citado en la nota 1 y a su desarrollo en la obra de Casado Velarde (1991). Destacables son también los trabajos "Etnolingüística" (Morant Marco y Díaz Rojo, 2005) y "Lenguaje y cultura" (Morant Marco, 2005), si bien ambos se limitan a describir, con interesantes ejemplos y reflexiones, temas de estudio de la disciplina, sin abordar los problemas epistemológicos de su definición (algo que se manifiesta explícitamente en Morant Marco, 2005: 125). Frente a ello, otras propuestas asimilan sin dudar la etnolingüística a la antropología lingüística, como es el caso de Cardona (1976), de Fernández Guizzetti (1957) y de Fernández y Hachén (1995), autores estos últimos que llegan a plantear una equiparación entre lingüística y etnolingüística (entendida, como 
reflexiones que han despertado en nosotros la actividad docente desarrollada en torno a esta materia y la lectura de diversos estudios que, a pesar de no haber sido adscritos necesariamente por sus autores al ámbito de la etnolingüística, pueden considerarse próximos a lo que aquí se intentará delimitar como su campo de trabajo ${ }^{4}$.

En definitiva, con las reflexiones que siguen se intentará definir y ubicar una disciplina que, a pesar de estar próxima en sus temas de interés a la antropología lingüística, puede caracterizarse como distinta de ella. Esta propuesta no pretende descubrir un nuevo campo de estudio del lenguaje, sino aprovechar aportaciones anteriores y complementarlas con la reflexión personal con el fin de pergeñar un marco teórico para una disciplina que debe afrontar el estudio de un aspecto fundamental -no anecdótico- del lenguaje. Con ello, este esbozo de definición pretende convertirse en una llamada de atención sobre la importancia y beneficio que tiene trabajar en una disciplina que ha quedado arrinconada por el poder de dos fuerzas que han centrado el interés de la lingüística contemporánea: por lo que respecta al papel del lenguaje en la vida del ser humano, por la sociolingüística; por lo que se refiere al estudio del lenguaje como materia científica, por el interés dedicado primero a la sintaxis (en especial por parte del funcionalismo y del generativismo) y, en la actualidad, a la "lingüística de la comunicación" (Gutiérrez Ordóñez, 2002: 84-88), ámbito en el que se engloban las disciplinas que mayor interés despiertan hoy en día (como son la lingüística del texto, la pragmática, el análisis de la conversación o la sociolingüística) y en el que podría tener cabida la propia etnolingüística.

\section{Una propuesta de definición de la etnolingüística}

Que el lenguaje y la cultura se encuentran relacionados es algo que actualmente se da por hecho, aunque la percepción de esa relación por parte de los lingüistas es bastante más reciente de lo que cabría suponer. De hecho, fue probablemente K. Vossler quien, basándose en las ideas de W. von Humboldt, llamó la atención por primera vez sobre la necesidad de estudiar las lenguas en relación con la cultura, si bien este planteamiento alcanzó su máxima expresión en la obra de E. Sapir -autor muy influido por el antropólogo F. Boas- y sus continuadores 5 . Por

queda dicho, en el sentido de antropología lingüística). Esa igualación entre antropología lingüística y etnolingüística es constante en el ámbito anglosajón y en los trabajos conectados con él, algo que queda patente, por mostrar solo algunos ejemplos representativos, en la recopilación de Garvin y Lastra de Suárez (1974), que, a pesar de titularse Antología de estudios de etnolingüistica y sociolingüística, presenta básicamente, en la sección de "Etnolingüística", trabajos de lo que aquí se considerará antropología lingüística; en el diccionario de Lewandowski (1995), donde se dan como equivalentes los términos etnolinguistics y anthropological linguistics (s.v. etnolingüística); o en la enciclopedia de D. Crystal, donde se ofrece una definición de etnolinguistics (Crystal, 1991: 412) que cuadra plenamente con la propuesta por Duranti (2000) para la antropología lingüística contemporánea, si bien etnolinguistics se distingue de anthropological linguistics, que viene a equipararse con la temática de la antropología lingüística tradicional (cfr. las dos vertientes de la antropología lingüística que comentamos en $\S 4.2$ ). Finalmente, puede mencionarse el tratamiento de Pottier (1970), quien atribuye a la etnolingüística la descripción de las taxonomías léxicas y gramaticales en tanto que reflejan la concepción que de la realidad tiene cada cultura, pero también otros campos de estudio que la convierten en una disciplina interesada por todo fenómeno comunicativo que escape a la rigidez de la lingüística descriptiva, interesada según él solo por lo "distintivo".

4 No son pocos los estudios que, a pesar de no haber sido concebidos o presentados como trabajos de etnolingüística, ayudan a delinear el marco teórico de esta disciplina. Es el caso, por ejemplo, de Ariza Viguera (2001), Baldinger (1985), Díaz Rojo (2002), Luque Durán y Manjón Pozas (1998), Prieto (2006), Reus Boyd-Swan (2004), Soler-Espiauba (1990) o Wierzbicka (1997). A ellos se pueden añadir nuestros trabajos de 2003 y 2005, en los que intentábamos desarrollar investigaciones a partir del marco teórico establecido por Coseriu (1981).

5 Vid. Casado Velarde (1991: 16-24), donde se expone con detalle una interesante historia de cómo se ha ido 
tanto, es posible afirmar que la etnolingüística surge de dos tradiciones distintas: el idealismo vossleriano, ajeno a planteamientos antropológicos; y el estructuralismo (si puede dársele ese nombre) de Sapir, en el que la conexión entre lingüística y antropología fue bastante estrecha (vid. Casado Velarde, 1991: 23). Ello explica que, como ya se ha señalado, a menudo se hayan identificado etnolingüística y antropología lingüística o, incluso, se haya llegado a considerar a la etnolingüística como una disciplina subsidiaria de la antropología lingüística ${ }^{6}$. Sin embargo, como también se ha mencionado, uno de los objetivos básicos de este trabajo es intentar mostrar que la etnolingüística puede concebirse como una disciplina diferenciada de la antropología lingüística (algo que no implica necesariamente asumir los postulados de Vossler).

Como primera vía de aproximación a la definición de la etnolingüística que se pretende alcanzar en este estudio, se presentarán las principales definiciones y caracterizaciones que de ella se han propuesto, sin entrar necesariamente a delimitar -entre otras cosas porque muchos de los autores ni siquiera lo hacen- si en esas definiciones se equiparan o no etnolingüística y antropología lingüística o, dicho de otro modo, si esas definiciones entroncan con una u otra de las dos tradiciones mencionadas ${ }^{7}$.

Según afirma Coseriu (1981: 10), la etnolingüística se ha ido desarrollando de forma fragmentaria y por diferentes vías, a menudo determinadas por los intereses ocasionales de quienes han querido dedicarse al estudio de las múltiples facetas que ofrece la relación entre el lenguaje y la cultura. Consecuencia de ello es que bajo el rótulo de etnolingüistica se han presentado trabajos centrados en objetivos diversos y se han formulado definiciones en ocasiones bastante divergentes. Haciendo un somero repaso, puede observarse que a la etnolingüística se le han atribuido campos de estudio o definiciones como las siguientes:

a) En sus orígenes (vid. Coseriu, 1981: 10-11; Fernández y Hachén, 1995: 1-2), se asignó a la etnolingüística el estudio de las lenguas "exóticas” y, dentro de ellas, de las lenguas ágrafas, conceptualizadas como la manifestación más representativa de esta categoría fundamentada en planteamientos a todas luces etnocentristas y acientíficos (vid. las interesantes críticas que se hacen de esta propuesta y de sus implicaciones en el pasaje citado de Fernández y Hachén así como en Morant Marco y Díaz Rojo, 2005: 2-3). En ese sentido, querer configurar una disciplina como responsable del estudio de las lenguas "exóticas" supone distinguir una lingüística "verdadera" (o "legítima"), encargada del estudio de las lenguas "de prestigio" (que serían, obviamente, las occidentales), y una "pseudolingüística” (la propia etnolingüística), cuyo fin sería estudiar "las otras" lenguas, consideradas como vehículos de culturas pintorescas y de cosmovisiones ajenas a la lógica y la objetividad que se les supone a las lenguas occidentales ${ }^{8}$. No parece pues coherente

tratando la relación entre lenguaje y cultura en la lingüística moderna.

6 Por ejemplo, en el diccionario de Alcaraz Varó y Martínez Linares (2005: s.v. etnolingüística), se afirma que esta disciplina está a caballo entre la antropología lingüística y la sociolingüística. De modo similar, Robins (1995: 565-567) conecta etnolingüística y lingüística antropológica planteando las tareas de la primera como una especie de concreción del ámbito de trabajo de la segunda.

7 Por otro lado, a la hora de presentar y comentar estas definiciones se obviarán ciertos usos del adjetivo etnolingüístico que podrían inducir a error dado que aluden en realidad a conceptos propios de la sociología del lenguaje (cfr. § 4). Nos referimos a nociones como las de grupo etnolingüistico, vitalidad etnolingüistica o actitudes etnolingüísticas (vid. entre otros Giles y Byrne, 1981; Appel y Muysken, 1996: 24; Amorós Negre 2014: 107).

8 Huelga decir -o al menos creemos que así debería ser- que todas las lenguas son iguales, dado que cada 
afirmar que la etnolingüística debe centrarse en el estudio de lo ajeno o extraño, dado que los rasgos de culturas alejadas no son ni más ni menos destacados que los que posee la propia; únicamente llaman más la atención del observador por la extrañeza que siempre despierta lo desconocido (obviamente, un miembro de una comunidad "exótica" también se sentiría sorprendido por muchos de los elementos de nuestra cultura), pero nada más. Todas las lenguas conectan con la cultura que las rodea, y no en aspectos secundarios o anecdóticos, sino en componentes fundamentales de la vida de la comunidad, de modo que los estudios etnolingüísticos pueden desarrollarse en cualquier lengua, sea la propia del investigador $\mathrm{u}$ otra distinta, independientemente de la cercanía que tenga con aquella.

b) Varios autores (vid. por ej. Fernández Guizzetti 1957: 75-77; Crystal, 1991: 412; Robins, 1995: 563-566; Alcaraz Varó y Martínez Linares, 2004: s.v. etnolingüística) han propuesto definir la etnolingüística como la disciplina encargada de estudiar el lenguaje y las lenguas en relación con los grupos étnicos y su comportamiento, de modo que su objetivo sería analizar cómo la lengua y su uso efectivo en la comunicación manifiestan la cultura del grupo étnico que la emplea. Este planteamiento, más próximo a lo que aquí se propondrá, tiene no obstante dos inconvenientes. Por un lado, limita el ámbito de la etnolingüística a una de las dos facetas en las que, como intentaremos demostrar, se manifiesta la relación entre el lenguaje y la cultura. Por otro, alude a un concepto, el de grupo étnico, que, al menos para algunas lenguas muy difundidas (caso del español, del inglés o del francés, por ejemplo), resulta difícil de sostener, al menos si se acepta que una etnia es, como se explicita en la última edición del DRAE, una "comunidad humana definida por afinidades raciales, lingüísticas, culturales, etc.”.

Tal vez por esta razón, Morant Marco y Díaz Rojo (2005) prefieren, simplemente, afirmar que la etnolingüística estudia el modo en que toda lengua refleja la cultura de los hablantes que la utilizan, sin aludir en ningún caso al concepto de etnia y dejando bien claro que ese reflejo no implica una correspondencia biunívoca entre una lengua y una cultura (Morant Marco y Díaz Rojo, 2005: 5-6)

c) También se ha planteado, como proponía ya Ferdinand de Saussure, que la etnolingüística debe estudiar las relaciones entre la historia de una lengua y la historia de la cultura del pueblo que la emplea (Lewandowski, 1995: s.v. etnolingüística).

una de ellas es el vehículo de la cultura de sus usuarios, se amolda a los intereses y a la cosmovisión de estos, y constituye un instrumento de expresión perfecto y plenamente acabado, suficiente para cubrir cualquier necesidad comunicativa. Por consiguiente, como bien han demostrado diversos autores (por ejemplo, en el ámbito hispánico, Moreno Cabrera [2000] y Tusón [1996]) a las lenguas no pueden aplicárseles adjetivos como exóticas, primitivas, desarrolladas, ricas, pobres, lógicas, objetivas... porque todas ellas son manifestaciones de una misma esencia y poseen idénticas características tanto en su función comunicativa como en sus relaciones con la vida social y cultural de quienes las emplean.

9 De hecho, la presencia del elemento compositivo etno- enturbia un tanto el nombre de la disciplina, pues induce a pensar que, se elija la definición que se elija, en ella debe estar presente el concepto de etnia (con todas sus conexiones con realidades como la raza y con aspectos tan idiosincrásicos como la religión o el derecho consuetudinario). Sin embargo, hay que tener en cuenta que ese elemento compositivo, al menos según el DRAE, significa no solo 'raza', sino también, de forma más laxa, 'pueblo' (de ahí que el propio diccionario académico defina la etnolingüística como "disciplina que estudia las relaciones entre la lengua y la cultura de uno o varios pueblos"). Quizás tampoco el concepto 'pueblo' sea del todo adecuado para caracterizar a la etnolingüística, pero al menos permite dar a etno- un sentido menos restringido y, en consecuencia, afín a la caracterización que propondremos de la etnolingüística como disciplina encargarda de estudiar las relaciones de la lengua con la cultura de cada comunidad humana. 
Este enfoque queda englobado en la definición que propondremos, pero supone una reducción drástica del campo de estudio de la disciplina, al limitarla a uno solo de los muchos ámbitos en los que se manifiesta la relación entre lenguaje y cultura. No obstante, tiene como contrapartida positiva que permite caer en la cuenta de que ciertas obras que han sido concebidas de forma totalmente ajena a la etnolingüística pueden aportar a esta datos muy interesantes ${ }^{10}$.

d) También se ha atribuido a la etnolingüística el estudio de las manifestaciones lingüísticas del folklore y de la cultura popular (cfr. Coseriu, 1981: 10; Morant Marco y Díaz Rojo, 2005: 2). Como la anterior, esta propuesta limita considerablemente el ámbito de la disciplina, al convertirla en una especie de rama subsidiaria de la etnografía general y situarla en la órbita de la línea de trabajo iniciada por la geografía lingüística (con sus atlas lingüísticos y etnográficos) y por el movimiento "Wörter und Sachen".

Frente a estas definiciones y planteamientos, quizás la propuesta más sólida sea la formulada por Coseriu (1981: esp. 10-14, 19-20, 25-29). En ese artículo que puede caracterizarse como programático, partiendo de la consideración de que definiciones y tratamientos anteriores no son suficientes para proporcionar un marco epistemológico adecuado para la etnolingüística, el lingüista rumano propone convertir esta disciplina en una lingüistica

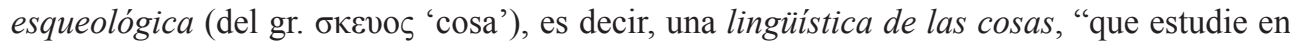
su totalidad la contribución del «conocimiento de las cosas» a la configuración y funcionamiento del lenguaje" (Coseriu, 1981: 11). Dicho de otro modo, para Coseriu la etnolingüística debe convertirse en el estudio de todas aquellas formas en las que la cultura ("las cosas") o, para ser más precisos, el conocimiento de la cultura ("el conocimiento de las cosas") interacciona con la lengua y con el uso que los hablantes hacen de ella. Asumida esta premisa, señala este estudioso que al investigar la relación entre el lenguaje y la cultura habrá que distinguir si el punto de partida es uno u otra, algo que permitirá dividir el campo de trabajo de la etnolingüística en dos ramas o secciones:

"si el objeto de estudio es el lenguaje, si se trata de los hechos lingüísticos en cuanto determinados por los «saberes» acerca de las cosas, se hace etnolingüística propiamente dicha o lingüística etnográfica; si, en cambio, el objeto de estudio es la cultura, si se trata de los «saberes» acerca de las «cosas» en cuanto manifestados por el lenguaje [...] se hace etnografía lingüística" (Coseriu, 1981: 12-13).

Además, este estudio de la relación lenguaje-cultura podrá enfocarse en cada uno de los tres planos de la comunicación lingüística -lenguaje, lengua y habla o, en la terminología del autor, hablar, lengua y discurso-, de modo que habrá "una etnolingüística del hablar en general, una etnolingüística de las lenguas y una etnolingüística de los discursos. Y lo mismo cabe esperar de la etnografía lingüística" (Coseriu, 1981: 14).

En definitiva, según esta propuesta, la etnolingüística sería una ciencia encargada de estudiar la íntima conexión existente entre lenguaje y cultura desde dos perspectivas, una dedicada a analizar cómo los hechos lingüísticos están condicionados por la cultura y otra

10 Nos referimos a obras tan significativas como la Historia de la lengua española de Lapesa (1981), de la que pueden extraerse, como se verá más adelante, numerosos datos de interés para estudios etnolingüísticos. 
interesada por descubrir los datos culturales que reflejan esos mismos hechos, cada una de las cuales podrá observar fenómenos propios del lenguaje en general, de las lenguas concretas o de los actos de habla efectivamente realizados. Tal es el esquema que, con diversos ejemplos y explicaciones, desarrolla con gran soltura y claridad Casado Velarde (1991: 49-100).

Creemos que tal planteamiento resulta muy interesante como punto de partida para encontrar una definición adecuada para la etnolingüística - de hecho, la que aquí se ofrecerá lo toma como base-, pero encontramos en él dos inconvenientes que nos impulsan a proponer una alternativa:

a) Por un lado, aunque la distinción entre etnolingüística y etnografía lingüística -que Coseriu presenta como paralela a la que suele establecerse entre sociolinguística y sociología del lenguaje- intenta oponer dos formas de estudiar una misma realidad a partir de un criterio riguroso, lo cierto es que no resulta fácil mantenerla en la práctica, salvo en casos extremos o, incluso, establecidos ad hoc. Partamos del ejemplo de los refranes - una de las formas lingüísticas en las que con más claridad se reflejan aspectos de la cultura que rodea a una lengua (cfr. § 5.1) - y, dentro de ellos, v. g., de los muchos que en español muestran un trasfondo religioso: si su estudio permite ver el reflejo de la religiosidad tradicional española, se haría etnografía lingüística; en cambio, si se intentan explicar sus valores significativos a partir de esa cultura religiosa de la que emanan, se estaría trabajando en el plano de la etnolingüística propiamente dicha. Sin embargo, para la mayor parte (o la casi totalidad) de los investigadores, analizar etnolingüísticamente estos refranes llevaría a una única conclusión: el hecho de que en español muchos refranes reflejen aspectos del cristianismo se explica por la importancia que esta religión ha tenido tradicionalmente en el ámbito hispano; o, dicho a la inversa, es posible explicar que muchos refranes reflejen la religiosidad tradicional española por la importante presencia en la cultura hispana del fenómeno religioso. Solo en el caso extremo de investigadores que desconocieran la importancia que ha tenido en esa cultura el cristianismo podría funcionar la distinción entre estos dos enfoques: un investigador que conociera los refranes pero no la tradicional religiosidad cristiana española (¿?) debería indagar en la cultura para explicarlos, haciendo así etnolingüística propiamente dicha; un investigador que no conociera nada de la cultura española ( $i$ ?) y se encontrara en un refranero con formas como $A$ quien madruga Dios le ayuda, A Dios rogando y con el mazo dando, A quien Dios se la dé San Pedro se la bendiga... estaría haciendo un estudio de etnografía lingüística que le permitiría descubrir que en la cultura española el cristianismo ha jugado un papel fundamental. Como puede deducirse, es más que improbable que se den situaciones como las descritas, pues un investigador que se acerque a las manifestaciones lingüísticas de una sociedad sin duda conocerá previamente algo de su cultura ${ }^{11}$.

b) Por otro lado, la afirmación de que el estudio de la relación entre lenguaje y cultura debe desarrollarse en los tres planos de la comunicación lingüística no parece compatible con el propio concepto de cultura. La cultura, por definición (cfr. § 3), es un

11 Incluso un estudio realizado sobre una comunidad de la que no se tienen conocimientos previos, al modo en que lo realizan a menudo los antropólogos, parte siempre primero del análisis de la cultura, al que podrá seguir el de la lengua, pero no al revés. Por tanto, un análisis etnolingüístico tendrá en cualquier caso como base un conocimiento anterior, por mínimo que sea, de la cultura. 
conjunto de realidades relacionadas con un determinado grupo humano, por lo que afirmar (cfr. Coseriu, 1981: 19; Casado Velarde, 1991: 49-52) que existen fenómenos etnolingüísticos propios del lenguaje en general, derivados de una especie de cultura universal, no parece muy consistente. Analicemos algunos de los ejemplos que al respecto presentan ambos autores: en ninguna lengua se emplean expresiones como, v.g., He visto un niño con manos (porque tener manos es una propiedad intrínseca de la anatomía humana); en cambio, otros enunciados aparentemente absurdos se explican por su valor expresivo, caso de Ser un mirlo blanco (dado que los mirlos nunca son de ese color); igualmente, las "normas generales del pensar humano" hacen incongruentes expresiones como Aquel hombre estaba vivo antes de morir (en este caso por ser tautológica), con independencia de la lengua en la que se transmitan $^{12}$. Tales ejemplos son, sin duda, muy interesantes porque permiten aludir y profundizar en importantes aspectos del intelecto y del lenguaje humano, pero no reflejan, a nuestro juicio, una suerte de cultura universal, ya que precisamente derivan de propiedades independientes de la cultura en la que se mueva el ser humano.

A pesar de estos puntos discutibles, la propuesta de Coseriu se tomará como base, tal como ya se ha afirmado, para presentar la definición de la etnolingüística que queremos proponer en este trabajo. Según ella, conceptualizaremos la etnolingüística como la rama de la lingüística "externa" que debe analizar cómo la cultura de una comunidad humana influye en la configuración y en el uso de la lengua empleada por esa comunidad, de modo que su objetivo será emplear el conocimiento de la cultura como recurso para explicar el porqué de determinados hechos lingüísticos - tanto del sistema como del uso- $y$, consecuentemente, encontrar en esos hechos huellas o reflejos de la cultura que subyace a ellos.

Esta propuesta de definición consta de varias premisas que se irán desarrollando en los próximos epígrafes:

a) La cultura de una comunidad (no de una etnia; ni siquiera de un "pueblo") influye en las lenguas. Pero ello no implica que exista una correlación biunívoca entre comunidad humana y cultura. A explicar este hecho y, de forma muy simplificada, el propio concepto de cultura, se dedicará el apartado $\S 3$.

b) La etnolingüística es una de las denominadas disciplinas "exolingüísticas", por lo que deberá ocupar una posición propia dentro del ámbito de la lingüística en general y de la externa en particular. Determinar esa posición, estableciendo los límites y conexiones de la etnolingüística con aquellas otras disciplinas con las que puede compartir ámbitos de interés, será el objetivo del epígrafe $\S 4$.

c) La influencia de la cultura sobre los hechos lingüísticos se cumple tanto en el sistema lingüístico como en el uso que se hace de él en la comunicación efectiva. Como se verá en el apartado $\S 5$, la repercusión de la cultura se manifiesta, por lo que se refiere al sistema, en el léxico, en la gramática, y, tal vez, en la fonología y en la fonética;

12 El concepto de "normas generales del pensar humano" (desarrollado en Coseriu, 1978: 20-21) alude a una serie de normas que rigen cualquier comunicación independientemente de la lengua en la que se realice, de modo que la infracción de dichas normas conllevará una incongruencia, esto es, una expresión no válida en ninguna lengua. Entre dichas normas destacan la no tautología, la necesidad del enlace apropiado o la no contradicción que deben presidir cualquier comunicación. 
mientras que, por lo que respecta al uso, la cultura condiciona la construcción de los discursos y de los actos de habla concretos. Partiendo de esta premisa, se podrá dar una explicación adecuada a determinados hechos y datos lingüísticos, los cuales serán a su vez portadores de las huellas de la propia cultura. De ese modo, serán muchos y variados los fenómenos y campos concretos que, en cada una de esos ámbitos lingüísticos, manifestarán simultáneamente las dos facetas a las que se alude en la propuesta de definición presentada.

El desarrollo de estos tres puntos servirá para completar la definición propuesta y, de ese modo, compensar la simplicidad que podría achacársele.

\section{Excurso: una noción de cultura}

Encontrar una definición satisfactoria de lo que es la cultura ha sido una preocupación constante de la antropología y de otras disciplinas interesadas por la vida social y cultural del ser humano, fruto de lo cual se han propuesto caracterizaciones muy detalladas y sutiles del concepto (puede verse una muestra en Morant Marco y Díaz Rojo, 2005: 3-4; y, especialmente, en Duranti, 2000: 47-81). Sin embargo, para los fines de este trabajo, creemos suficiente asumir una noción de cultura que, sin llegar a la profundidad teórica de otras definiciones, proporcione a la etnolingüística un marco de referencia lo suficientemente sólido y coherente como para dar cabida de manera satisfactoria a los diversos temas de estudio que puede abordar esta disciplina (cfr. $\S 5$ ).

Para alcanzar ese objetivo, se tomarán como punto de partida las definiciones que de la palabra cultura se proponen en los diccionarios generales del español. Así, dejando de lado acepciones como la de 'cultivo, crianza' (mantenida en la actualidad únicamente en el elemento compositivo -cultura de voces como acuicultura o apicultura) o la de 'conocimientos adquiridos por una persona mediante el estudio, las lecturas, los viajes, etc.', se asumirán aquí definiciones como las siguientes ${ }^{13}$ :

- "Conjunto de modos de vida y costumbres, conocimientos y grado de desarrollo artístico, científico, industrial, en una época o grupo social” (DRAE).

- "Conjunto de los conocimientos, grado de desarrollo científico e industrial, estado social, ideas, arte, etc., de un país o una época" (Diccionario de Uso del Español, $2^{\mathrm{a}}$ edición).

- "Conjunto de modos de vida, conocimientos y grado de desarrollo de una colectividad humana o de una época" (Diccionario del Español Actual).

- "Conjunto de conocimientos y actividades científicas, industriales y artísticas de un pueblo, país o una época" (Gran Diccionario de la Lengua Española, editorial Larousse).

El análisis de estas definiciones permite destacar dos aspectos fundamentales.

En primer lugar, en todas ellas la palabra cultura se asocia a un "conjunto" de realidades que se circunscriben a dos grandes ámbitos: el de lo inmaterial (por su carácter espiritual, o psíquico, o mental...) y el de lo material. En ese sentido, puede considerarse que los resultados de la cultura son productos tanto inmateriales como materiales, produc-

13 Consideramos suficientemente conocidos los diccionarios manejados, de ahí que obviemos su cita bibliográfica. 
tos que se contraponen a lo que es la naturaleza en sí misma (cfr. Casado Velarde, 1991: 11-12, cuyas ideas asumimos en esta exposición). Dicho de otra manera, la cultura puede concibirse como todo aquello que no es naturaleza: para Casado Velarde, la naturaleza es lo que está dado al ser humano de manera inmediata - es decir, sin su intervención-, ya sea como parte de su ser (su cuerpo y sus órganos, su mente...), ya sea como parte de su entorno (la tierra, los ríos, los seres vivos...); en cambio, la cultura sería el conjunto de los productos elaborados por el ser humano al actuar, tanto física como mentalmente, sobre esa naturaleza. De este modo, la cultura equivale a lo que también se denomina civilización material y civilización espiritual, pues engloba todos los productos de la actividad humana, es decir, todo aquello que el ser humano crea, ya sea física o mentalmente: por un lado, productos de la industria y la artesanía, instrumentos, herramientas, edificaciones, obras artísticas... (es decir, objetos surgidos de la manipulación física ejercida por el ser humano sobre las realidades de la naturaleza); por otro, costumbres, creencias, ideologías, prácticas de interrelación social y la propia interpretación de la naturaleza y de la vida (esto es, ideas procedentes de la reflexión que el ser humano realiza acerca de su entorno y de sí mismo).

En segundo lugar, estas definiciones presentan la cultura como algo concreto y específico, asociado a un momento o a un lugar, o, dicho de otra manera, a una comunidad humana determinada (que es, obviamente, la que ocupa ese lugar o ese momento y crea los objetos e ideas de la cultura) ${ }^{14}$. No obstante, es fundamental tener en cuenta (cfr. Morant Marco y Díaz Rojo, 2005: 3-4), que el hecho de que la cultura sea algo compartido por un grupo humano no implica necesariamente que ese grupo sea el mismo que emplea una lengua determinada. Ello puede ocurrir en comunidades reducidas y localizadas (las preferidas de los estudios antropológicos y etnográficos tradicionales), pero no se da en absoluto en el caso de las lenguas con una importante extensión geográfica, con las cuales no se relaciona una única cultura, sino muchas y variadas, tanto por motivos sincrónicos como por motivos diacrónicos. Sincrónicamente, es obvio que existen, por un lado, culturas más amplias que las propias lenguas (por ejemplo, las que podríamos llamar "cultura occidental", "cultura cristiana" o "cultura de masas") e intercambios culturales que determinan que elementos de una cultura se transmitan a otra u otras (la "interculturalidad"); y, por otro, "subculturas" y contraculturas ${ }^{15}$. Diacrónicamente, no hay que olvidar que toda cultura evoluciona, lo cual determina que se vayan superponiendo estratos o capas de culturas de distintas épocas que, en un momento dado, conviven en mayor o menor medida.

En definitiva, la cultura, entendida como el conjunto de los productos materiales e inmateriales que una comunidad humana crea al actuar física o mentalmente sobre la naturaleza, es una realidad que se relaciona con la lengua, pero sin que exista una dependencia biuní-

14 Esta es la razón por la que se ha señalado en $\S 2$ que el concepto de "cultura universal" no parece sostenible. 15 Con el término subcultura queremos aludir, sin matiz peyorativo (valor que sí está presente en las definiciones que de esta palabra aparecen en el Diccionario de Uso del Español y en el Diccionario del Español Actual), a las culturas concretas que conviven dentro de otra más general. Por ejemplo, y sin entrar en disquisiciones que no son competencia directa de este trabajo, lo que serían la cultura española, la venezolana o la argentina dentro de la hispana o, en un plano aún más concreto, la cultura andaluza, la castellana o la extremeña dentro de la española. En definitiva, con esta palabra se alude al hecho de que aunque todos los hablantes de una lengua puedan compartir rasgos culturales, existen también otras culturas concretas, dispuestas en círculos concéntricos que corresponden a manifestaciones culturales cada vez más específicas. Por su parte, el término contracultura aludiría a un tipo muy concreto de subcultura caracterizado por el deseo de subvertir los valores de la cultura dominante. 
voca entre ambas, pues una misma lengua puede (o, mejor, suele) tener asociadas diversas culturas y una misma cultura puede extenderse por más de una lengua. Este hecho debe ser tenido muy en cuenta a la hora de abordar un estudio etnolingüístico, pero no invalida la definición propuesta para la disciplina, sino que, simplemente, la matiza.

\section{El lugar de la etnolingüística entre los estudios del lenguaje}

El segundo escalón en el camino marcado en este trabajo de proponer una caracterización completa de la etnolingüística lo constituirá el intento de ubicarla dentro del conjunto de las disciplinas lingüísticas, señalando sus límites respecto de ellas pero también sus conexiones e intersecciones.

Con tal fin, se revisará la posibilidad de disociar la etnolingüística de la sociolingüística y, sobre todo, de la antropología lingüística, y se comentarán las conexiones que la etnolingüística tiene con disciplinas como la pragmática y el análisis del discurso.

\subsection{Etnolingüística vs. sociolingüística}

Aunque sociedad y cultura forman una simbiosis, no parece difícil separarlas desde un punto de vista analítico y, por consiguiente, en el estudio de su relación con el lenguaje ${ }^{16}$. Por tanto, parece sencillo, en principio, deslindar la sociolingüística, preocupada por la dimensión social de los hechos lingüísticos, y la etnolingüística, interesada por su vertiente cultural. Pero la realidad es que esa simbiosis entre sociedad y cultura determina que haya hechos y fenómenos lingüísticos sobre cuya adscripción a una u otra disciplina podrían suscitarse dudas.

Veremos, a modo de ejemplo, algunos de esos puntos fronterizos:

a) El estudio de la influencia que ejercen en la variación lingüística factores como el sexo o la edad ha sido tradicionalmente atribuido a la sociolingüística por la asunción de que tales factores son sociológicos (cfr. por ejemplo Moreno Fernández, 1998: 3445). No obstante, no hay que olvidar que las variaciones lingüísticas debidas al sexo o a la edad no se fundamentan en cuestiones biológicas, sino en factores culturales; en concreto, en los papeles que la ideología dominante en una sociedad atribuye a cada sexo y a cada generación. Ahora bien, esa determinación cultural de los roles generacionales y sexuales se actualiza en la estructuración de la sociedad y en las relaciones intergrupales, por lo que resulta plenamente acertado que su reflejo en el lenguaje sea asignado al campo de la sociolingüística.

b) Las llamadas actitudes lingüísticas (mejor que "etnolingüísticas", cfr. nota 7) que determinan la elección de lenguas en los intercambios comunicativos y el comportamiento hacia ellas de los hablantes son objeto de la sociolingüística. Estas actitudes tienen su raíz en las ideologías (i. e., en un componente fundamental de la cultura) pero dado que, como en el caso anterior, se manifiestan en comportamientos y

16 Cierto es que la llamada Etnografía de la comunicación se ha presentado a sí misma como una disciplina interesada por el análisis del papel de la vida sociocultural del ser humano en la lengua (cfr. Hymes, 1964: 49-52), pero esta disciplina se centra en realidad en los aspectos culturales de la comunicación, que analiza desde una perspectiva muy próxima a la que plantea la moderna antropología lingüística (cfr. Moreno Fernández, 1998: 301303; Calsamiglia Blancafort y Tusón, 1999: 19-20; y lo dicho en el apartado § 4.2). 
relaciones sociales, parece correcto asignar su estudio a la sociolingüística o, si se prefiere, a la sociología del lenguaje (vid. Moreno Fernández, 1998: 179-189).

c) Finalmente, puede mencionarse la cuestión de la influencia que ejercen las pautas culturales en el modo en el que se desarrolla un determinado intercambio comunicativo (la conocida competencia comunicativa ${ }^{17}$ ). En este hecho confluyen también lo cultural y lo social, y de forma posiblemente más compleja que en los ejemplos anteriores, pues el fenómeno puede estudiarse desde ambas perspectivas. Por un lado, puede estudiarse , por ejemplo, cómo la cultura de una determinada comunidad condiciona la forma de los intercambios comunicativos (el modo en que se organizan los turnos, las expresiones y recursos que se emplean para ceder el turno...), algo que debe quedar para la etnolingüística ${ }^{18}$. Por otro, se puede estudiar cómo esa construcción de los intercambios repercute en las relaciones sociales y constituye, por ende, una forma de contacto entre las personas, lo cual sería objeto de estudio de la sociolingüística.

En definitiva, los contactos entre sociolingüística y etnolingüística radican en que, debido a la íntima relación existente entre sociedad y cultura, los hechos sociales pueden tener una base cultural y la cultura puede incidir en las relaciones sociales. Pero esto no es óbice para que la investigación lingüística separe los fenómenos estudiados según la faceta que predomine en ellos, dado que una cosa es que haya aspectos culturales que repercuten en la dimensión social del lenguaje (algo que no deja de pertenecer al campo de la sociolingüística) y otra que el influjo de la cultura sobre ciertos hechos lingüísticos tenga un reflejo en la vida social (hechos que no por ello dejarán de interesar a la etnolingüística).

\subsection{Etnolingüística vs. antropología lingüística}

A la hora de situar a la etnolingüística entre las ciencias del lenguaje, el límite más difícil de establecer, o incluso de admitir para determinados investigadores, es, sin duda, el que pueda existir entre ella y la antropología lingüística, pues es obvio que los puntos de contacto entre ambas disciplinas y los temas de interés compartidos son numerosos. De hecho, como ya se ha comentado, no es infrecuente que estas dos ciencias se identifiquen y que por ello sus denominaciones se presenten como sinónimas (por ejemplo, en Cardona, 1976: 16).

No obstante, creemos posible proponer argumentos que muestren, cuando menos, que la etnolingüística, tal como se pretende perfilarla en este estudio, no es idéntica a la antropología lingüística. Para ello, partiremos de que la antropología lingüística (cfr. Duranti, 2000: 2030, 36-45; Palmer 2000: 31-48) presenta dos líneas de trabajo claramente diferenciadas. Por un lado, la iniciada por Boas, llamada a veces "lingüística boasiana", interesada sobre todo por analizar cómo los elementos de la lengua, en especial los léxicos y gramaticales, pueden

17 Sobre este concepto, vid. § 5.4. La dualidad de la que hablamos se manifiesta en el hecho de que a menudo los sociolingüistas incluyen en sus investigaciones y manuales el tratamiento de la competencia comunicativa (vid., por ejemplo, Moreno Fernández, 1998: 203-206; García Marcos, 1999: 284-288)

18 En principio, estos aspectos caen dentro del campo de estudio del llamado análisis de la conversación (vid. por ej. Tusón Valls, 1997: 54-66), pero, como intentaremos justificar (cfr. § 4.4 y 5.4), no dejan de ser objeto de interés para la etnolingüística. 
reflejar la cosmovisión de la comunidad que emplea esa lengua ${ }^{19}$. Por otro, la vertiente contemporánea, representada por autores como Duranti, que centra su atención en el estudio de las interacciones comunicativas como prácticas de interrelación social condicionadas por factores culturales propios de cada comunidad humana ${ }^{20}$. Se trata, pues, de dos líneas de trabajo que, combinadas, permiten asignar a la antrología lingüística el estudio de la relación que establecen tanto el sistema de la lengua como su uso efectivo en la comunicación con la cultura de la sociedad correspondiente, algo que viene a coincidir, de forma global, con la definición que se ha propuesto en este trabajo para la etnolingüística. Sin embargo, es posible encontrar diferencias entre ambas propuestas teóricas, diferencias que pueden subsumirse en tres:

a) En primer lugar, aunque muchos de los temas que entran en el ámbito de la etnolingüística pueden ser estudiados por la antropología lingüística y viceversa, es posible encontrar temas privativos de cada de ellas (o, al menos, temas que no parecen ser de interés para la otra disciplina). Por ejemplo, como veremos en $\S 5.1$, la etnolingüística puede encontrar fuentes de datos relevantes para sus objetivos en elementos lingüísticos como los topónimos y los extranjerismos o en el estudio de las connotaciones y las etimologías de las palabras, lo cual no se encuentra entre los temas tratados por la antropología lingüística. Del mismo modo, no parece que a la etnolingüística le interesen aspectos estudiados por los antropólogos lingüistas como la participación -entendida como la correlación de los actos comunicativos con la intervención de los individuos en la vida de su comunidad (Duranti, 2000: 43-44 y 375-377) - o como la relación entre el bilingüismo y el comportamiento sociocultural de los hablantes (Cardona, 1976: 95-97).

b) Por otro lado, tal como las concebimos aquí, antropología lingüística y etnolingüística pertenecen a paradigmas teóricos diferentes. Como afirma Coseriu (1981: 10) y asumimos en este trabajo, la etnolingüística es una "disciplina lingüística, no etnológica ni etnográfica" que estudia la variación del lenguaje y de las lenguas en relación con la civilización y la cultura. En cambio, siguiendo a Duranti (2000: 2223), la antropología lingüística sería una de las ramas de la antropología general, que se interesa por el estudio del lenguaje

a través del prisma de los intereses antropológicos, entre los cuales están: la transmisión y reproducción de la cultura, la relación entre los sistemas culturales y otras formas de organización social, y el papel de las condiciones materiales de existencia en la comprensión que los individuos tienen del mundo (Duranti, 2000: 23).

19 Concreción de esta línea de trabajo sería, a nuestro entender, la llamada etnosemántica, cuyo foco de interés estaría en el estudio de cómo cada lengua estructura léxicamente determinadas parcelas de la realidad mediante taxonomías condicionadas por la cosmovisión de la comunidad correspondiente (cfr. Palmer, 2000: 40-43). No obstante, Palmer (2000: 31-48) considera la etnosemántica como una de las corrientes de la antropología lingüística, junto con la lingüística boasiana y la etnografía de la comunicación (cfr. nota siguiente).

20 Este planteamiento coincide, grosso modo, con el propuesto por Hymes para la etnografía de la comunicación, de ahí que ambas propuestas teóricas puedan identificarse como una sola disciplina. Prueba de ello es, por ejemplo, el propio trabajo de Duranti (1992) o la inclusión en el volumen editado por este mismo estudioso en 2001 del célebre artículo de Hymes "On Communicative Competence". Cfr. también Palmer (2000: 44-48), quien menciona a Duranti entre los representantes de la etnografía de la comunicación, la cual, como queda dicho en la nota anterior, constituye para él una de las ramas de la antropología lingüística. 
Dicho más sencillamente, y aunque parezca tautológico, la etnolingüística es una disciplina lingüística que deberá ser desarrollada por lingüistas, mientras que la antropología lingüística es una disciplina antropológica de la que se ocupan antropólogos. Desde esa perpectiva, es posible afirmar que la etnolingüística tiene el lenguaje como objetivo prioritario de su trabajo, puesto que su propósito es estudiar los hechos lingüísticos en cuanto condicionados por la cultura; en cambio, la antropología lingüística toma el lenguaje como medio para alcanzar un fin, puesto que al analizar la lengua y su empleo en la comunicación lo que le interesa es cómo el lenguaje constituye uno de los componentes que configuran la esencia del ser humano y de su vida social y cultural. Esta diferencia explica, además, que mientras que la etnolingüística puede desarrollar sus estudios en referencia a cualquier lengua, la antropología lingüística suele preferir el estudio de comunidades limitadas y bien localizadas (vid. Duranti, 2000: 375-376).

c) Finalmente, y en relación con lo anterior, hay que destacar que el método de trabajo de la antropología lingüística es muy distinto del que debería emplear, tal como se la concibe aquí, la etnolingüística. El antropólogo lingüista aborda sus investigaciones como parte de (o apoyadas en) la investigación etnográfica global de una comunidad (vid. Duranti, 2000: 125-223 y, en especial, 126-142), investigación que se basa en el trabajo de campo y en el contacto continuado con la comunidad estudiada y que tiene la finalidad, como queda dicho, de analizar el lenguaje como una parte más de la vida social y cultural de cada comunidad. En cambio, un etnolingüista trabaja (o podría trabajar) de forma diferente. Por un lado, no es imprescindible que realice un estudio de campo, pues puede hacerlo también a partir de fuentes documentales, algo que dependerá del tema concreto que se aborde. Por otro, aun cuando realice una investigación de campo, no necesita integrarse en la vida de la comunidad correspondiente ni estar en contacto permanente con sus miembros, dado que su objetivo no es situar los datos lingüísticos como un componente más de la vida de esa comunidad, sino analizarlos en sí mismos y explicarlos por su relación con la cultura.

En definitiva, creemos suficientemente justificado separar estas dos disciplinas, lo cual no implica afirmar, en absoluto, que la etnolingüística no pueda aprovechar los datos e informaciones que proporcione la antropología lingüística, pues, como queda dicho, ambas comparten ámbitos de interés y, por tanto, temas de estudio. Lo que las diferencia son el marco epistemológico, el enfoque, los fines y los métodos de cada una, de modo que la etnolingüística podrá tomar para sí (parte de) los datos de la antropología lingüística, pero reformulándolos y adaptándolos a su propio marco teórico, que no es otro que el de la lingüística general y, dentro de él, el de las disciplinas interesadas por analizar el papel del lenguaje en la vida del ser humano ${ }^{21}$.

\subsection{Etnolingüística y pragmática}

Para alcanzar una adecuada ubicación de la etnolingüística importa también establecer sus relaciones con la pragmática, en este caso no porque los límites entre estas disciplinas no estén claros, sino porque sus temas de interés confluyen en parte $y$, de hecho, pueden retroalimentarse.

21 No es este lugar para desarrollar cuál puede ser esa metodología común a las disciplinas "exolingüísticas". Nos remitimos para ello a referencias como Fernández Pérez (1986) o Rotaexte (1990). 
Si asumimos que la pragmática se interesa por estudiar el empleo efectivo del lenguaje y los fenómenos, semánticos y comunicativos, que se derivan de ello (cfr. por ejemplo Escandell Vidal, 1996: 13-14), es obvio que su campo de estudio coincide en parte con el de la etnolingüística, dado que esta, como se ha postulado en este trabajo, debe estudiar cómo la cultura determina la lengua tanto a nivel del sistema como a nivel de su uso en la comunicación. Partiendo de ahí, no es difícil percibir que el interés de la etnolingüística por el uso efectivo del lenguaje la pone en contacto con la pragmática desde el momento en que muchos de los aspectos que esta estudia tienen una dimensión cultural, algo que a veces parece pasar desapercibido para los especialistas de esta disciplina ${ }^{22}$.

Por consiguiente, será posible establecer entre ambas disciplinas una colaboración mutua, ya que la etnolingüística podrá aprovechar nociones propias de la pragmática (v. g., acto de habla, implicatura, acto indirecto, ostensión, fórmula de cortesía...) para analizarlos a la luz de la cultura, devolviéndole así a esta la constatación de que esos fenómenos, si bien pueden ser universales en sí mismos, se conforman a menudo de modos distintos según cada cultura. Basten un par de ejemplos muy simples:

a) Probablemente todas las lenguas emplean actos de habla indirectos, pero un acto indirecto que desde nuestro etnocentrismo podría parecernos universal como es el de usar una estructura oracional interrogativa para proferir una orden ( ¿Te importaría guardar silencio?, ¿Por qué no te callas?...), solo se da en ciertas culturas (cfr. Escandell Vidal, 1996: 73-74).

b) Leech (1983), al presentar su teoría sobre la cortesía verbal, distingue distintos tipos de enunciados según su grado de cortesía (corteses, indiferentes, conflictivos y descorteses) y expone algunos de los recursos que sirven para modificar ese grado de cortesía, sobre todo en los casos en los que el enunciado se presenta como conflictivo (actos indirectos, paráfrasis, empleo de fórmulas especiales...). Como es fácil de entender, el catálogo de actos atribuibles a cada categoría difiere de unas sociedades a otras y, más en concreto, son específicos de cada cultura tanto el modo en que se usan los recursos para favorecer la cortesía de los enunciados como muchos de esos recursos (cfr. Escandell Vidal, 1996: 136-138).

\subsection{Etnolingüística y análisis del discurso y análisis de la conversación}

Finalmente, puede mencionarse la relación que se establece entre etnolingüística por un lado y análisis de la conversación y análisis del discurso por otro ${ }^{23}$, relación que se basa en los mismos parámetros que la señalada en el epígrafe anterior: el modo en que se construyen los géneros discursivos y su tipología, así como la forma en que se desarrollan las conversaciones, aunque siguen en ciertos aspectos pautas universales, tienen una conformación concreta que muchas veces depende de la cultura a la que se asocia una

22 Ya en su obra, publicada en lo que podríamos considerar los "albores" de la pragmática, Cardona (1976: 215) criticaba el etnocentrismo de los filósofos del lenguaje iniciadores de esta corriente, muy proclives a identificar como universales fenómenos condicionados por la cultura.

23 Que las presentemos juntas no quiere decir que identifiquemos ambas disciplinas. De hecho, consideramos que el análisis de la conversación es, en cierto modo, una concreción del análisis del discurso (cfr. Tusón Valls, 1997: 12-14; Calsamiglia Blancafort y Tusón Valls, 1999: 20-21). 
lengua. Por tanto, la etnolingüística podrá analizar muestras reales de discursos (orales o escritos) para descubrir cómo los géneros discursivos en general y la conversación en concreto están en gran medida mediatizados culturalmente.

En ese sentido, el condicionamiento cultural de la conversación queda claramente expuesto en el grueso de la obra de Duranti (2000: esp. 329-374), pues es uno de los focos fundamentales de su investigación. Respecto de ello, este autor llama la atención sobre el hecho de que muchas veces los especialistas en antropología lingüística han criticado a los analistas de la conversación su falta de atención al contexto histórico y cultural (vid. Duranti, 2000: 356-357).

De modo similar, hay que tener en cuenta cómo muchos géneros narrativos, a pesar de ser prácticamente universales, tienen conformaciones distintas según las culturas, como ocurre por ejemplo con los textos periodísticos, que, a pesar de presentar una tipología general compartida de forma casi universal, muestran diversas manifestaciones concretas y estructuras según las culturas (cfr. Casado Velarde, 1991: 92).

\subsection{Conclusión}

El recorrido seguido en esta sección para buscar la posible ubicación de la etnolingüística dentro del conjunto de las ciencias del lenguaje nos lleva a concluir que esta es una de las disciplinas de la llamada lingüística externa o macrolingüística, de modo que, como todas las que se incluyen en este ámbito, tiene como foco de interés los elementos del lenguaje (sean del sistema o del uso) aunque los analiza a partir de su conexión con otra faceta de la vida humana; en este caso, la cultura. A partir de ahí, puede decirse que esta disciplina establece diversas conexiones con otras de su mismo ámbito o interesadas por el lenguaje:

a) Mantiene relaciones estrechas con la sociolingüística, pero los puntos de contacto entre ambas emanan de la simbiosis que existe entre sociedad y cultura, de modo que discriminando si es lo cultural o lo social lo que predomina podrán separarse los temas de estudio en los que más se percibe esa simbiosis.

b) Su proximidad con la antropología lingüística es innegable por lo que respecta a los puntos de interés, pero estos no coinciden plenamente $y$, sobre todo, es posible afirmar que se trata de disciplinas que se enmarcan en ámbitos epistemológicos diferentes, algo que se manifiesta en sus diferentes enfoques, objetivos y métodos de trabajo.

c) Puede colaborar con otras disciplinas (pragmática, análisis del discurso y análisis de la conversación), ya que, al coincidir en parte con sus temas de estudio, enriquecerá los postulados de aquellas mostrando que en muchas ocasiones los fenómenos que les interesan tienen un condicionamiento cultural.

En definitiva, la etnolingüística es una disciplina a la que puede atribuirse un ámbito de estudio específico que, no obstante, no es exclusivo suyo, lo cual es, sin duda, uno de los factores que explican que haya recibido escasa atención por parte de la lingüística moderna. Sin embargo, dándole a ese ámbito de estudio un enfoque propio -el que hemos intentado demostrar que le diferencia de la antropología lingüística- es posible encontrar una disciplina que puede ofrecer tratamientos distintos para temas más o menos conocidos y estudiados. Mostrar cuáles son esos temas y el tratamiento que puede dárseles es el objetivo del resto de este artículo. 


\section{5. Ámbitos y temas de estudio de la etnolingüística}

El estudio del condicionamiento cultural del lenguaje puede enfocarse, como ya se ha mencionado, respecto tanto del sistema como del uso. De este modo, si se asume la tradicional división que suele establecerse de las lenguas en tres niveles básicos -léxico, gramática y fonología- y se atribuye al uso un campo propio y específico, serán cuatro los ámbitos de trabajo de la etnolingüística, en cada uno de los cuales podrán analizarse diversos hechos y fenómenos que mostrarán la influencia que ejerce la cultura sobre el lenguaje y, consecuentemente, cómo este refleja huellas más o menos marcadas de la propia cultura.

Partiendo de ahí, esta sección se dedicará a la presentación de los ámbitos en los que pueden desarrollarse las investigaciones de la etnolingüística $\mathrm{y}$, a modo de concreción, de algunos de los temas que pueden estudiarse en cada uno de ellos. Esos temas, y los ejemplos con los que se ilustra su presentación, proceden tanto de la bibliografía manejada para elaborar este estudio como de la aportación personal derivada de nuestro contacto docente con la disciplina y de las investigaciones que al hilo de ella hemos desarrollado en otros trabajos.

Pero antes de desarrollar ese aspecto, conviene hacer una observación importante.

Los temas de estudio que se presentan seguidamente corroboran la premisa fundamental de nuestra definición de la etnolingüística: la cultura influye en determinados hechos lingüísticos y, consecuentemente, estos reflejan la cultura. Pero ese reflejo no siempre tiene la misma visibilidad para los hablantes, ya que, según los casos concretos, habrá elementos lingüísticos de cuyo valor cultural los hablantes sean conscientes, otros de los que lo serán solo en parte (y tal vez a partir de la reflexión inducida) y otros de los que seguramente no lo sean en absoluto. Partamos de la comparación entre ejemplos tomados de un solo ámbito, el de las unidades del discurso repetido (cfr. § 5.1):

(1) A quien madruga Dios le ayuda, A Dios rogando y con el mazo dando, Cada uno en su casa y Dios en la de todos.

(2) A las primeras de cambio, Estar al quite, Cambiar de tercio, Cortarse la coleta ${ }^{24}$.

(3) Estar en la picota, Colgar un sambenito, A buenas horas mangas verdes.

Si se comparan estos tres grupos de unidades, es fácil constatar que cualquier hablante medio de español percibiría en las de (1) la influencia que la religión cristiana ha tenido tradicionalmente en la sociedad española; en cambio, conocer que las de (2) proceden del ámbito taurino y, por consiguiente, reflejan la importancia que, sobre todo en el pasado, tuvo esta actividad en la cultura española, no está al alcance de todos los usuarios; y, finalmente, el transfondo cultural de las de (3) solo será perceptible para personas concretas que, por intereses individuales o simplemente por cultura adquirida, hayan tenido conocimiento de él.

Con esta comparación, defendemos -frente a las afirmaciones de que la lengua refleja "la actualidad de la cultura" (Coseriu, 1981: 17; Casado Velarde, 1991: 42-43) y de que en ella hay elementos del pasado que "no representan culturalmente nada" (Morant Marco y Díaz Rojo, 2005: 15)- que las lenguas contienen numerosos elementos conectados con hechos culturales pretéritos que, a pesar de ser más o menos opacos para los hablantes, no por ello

24 Todas estas expresiones figuran en Reus Boyd-Swan (2004), donde se dan explicaciones detalladas sobre su origen y significado. 
dejan de ser interesantes para la etnolingüística. De hecho, es importante estudiar también estos elementos relacionados con aspectos de culturas pasadas, pero teniendo en cuenta la posible vigencia o no de los datos culturales subyacentes a cada hecho lingüístico, pues una cosa son los datos del estudio científico y otra los que están en la mente del hablante, entre los cuales hay relaciones diversas, algo de lo que el investigador debe dar cuenta ${ }^{25}$. En definitiva, estudiar datos en los que se manifiesta una influencia cultural del pasado puede ser útil porque estos muestran huellas culturales interesantes, y el investigador puede dar cuenta de ellos por mucho que no sean ya visibles para los hablantes de una determinada sincronía; lo fundamental es que la investigación etnolingüística deslinde la interpretación histórica de los hechos y la de su funcionamiento en la mente del hablante ${ }^{26}$.

\subsection{El estudio etnolingüístico del léxico}

El léxico -entendido como el repertorio constituido tanto por las palabras como por las unidades que conforman lo que Coseriu (1977: 113-118) denominó discurso repetido ${ }^{27}-$ es sin duda el ámbito lingüístico donde más directamente se observa la repercusión de la cultura, de ahí que sean muchos los aspectos concretos en los que se puede constatar y, por ende, analizar esa influencia. De ellos, destacaremos:

a) La conformación del léxico en función del entorno circundante. Como bien explican Morant Marco y Díaz Rojo (2005: 10-16), el lenguaje es una valiosa guía para conocer cómo las sociedades se adaptan a su entorno natural, social, material y sobrenatural, de modo que muchas palabras serán el reflejo de cómo ha conformado

25 Precisamente, en nuestro trabajo de 2005 intentábamos mostrar cómo el investigador de la relación lenguajecultura no debe olvidar si ese influjo de la cultura sobre los hechos lingüísticos es o no visible para los hablantes, ya que de no hacerlo puede falsear los datos que ofrezca a la comunidad científica. Por ejemplo, según Palmer (2000: 157-174), la distribución de los sustantivos de las lenguas bantúes en catorce clases en función de los clasificadores a los que se asocian está relacionada con la visión que esta etnia tiene del mundo sobrenatural. Sin embargo, no es lo mismo explicar el sistema de clasificadores de estas lenguas por la espiritualidad actual de ese pueblo, que por el influjo de primitivas creencias que han dado lugar a elementos que para los hablantes no son más que elecciones gramaticales obligadas. Dicho de otro modo, la afirmación de Palmer -cuya validez intrínseca no se cuestiona aquí- debe ser avalada por un estudio previo que determine si las creencias que han originado el sistema de clasificación de las lenguas bantúes siguen vigentes en la mente de los hablantes.

26 Incluso, se dan casos llamativos en los que un hecho cultural que influyó en el pasado en la lengua pervive de forma latente. Por ejemplo, Sol y Luna son masculino y femenino por motivos culturales desconocidos para el hablante actual (por la asociación con las figuras correspondientes de la mitología grecolatina, esto es, con Selene y Febe en el caso de la Luna y con Helio y Apolo en el del Sol), pero muchas veces se siguen concibiendo como hombre y mujer, como de hecho demuestran los nombres populares que se les dan (Lorenzo y Catalina), canciones infantiles (como la propia "El sol se llama Lorenzo y la luna Catalina") o las formas en que suelen dibujarse estos astros, y no solo por parte de los niños.

27 Este estudio no necesita abordar el arduo problema que supone determinar el lugar de las unidades del discurso repetido en la arquitectura de la lengua, de ahí que a efectos prácticos y por comodidad teórica se equiparen con las palabras como componentes del léxico, aunque también es cierto que esa conexión tiene su fundamento en el hecho, innegable, de que estas unidades se aprenden y almacenan en el acervo lingüístico del mismo modo que el vocabulario de la lengua (de ahí el conocido concepto de lexía acuñado por Pottier). Por otro lado, como afirma con razón García-Page (2004: 25-26), el concepto "discurso repetido" es demasiado abarcador para la investigación de la fraseología y fenómenos afines, pero precisamente esa amplitud evita entrar en complicaciones sobre el estatus y tipología de estas unidades que tampoco son de la incumbencia de este trabajo. 
e interpretado esos entornos la sociedad que emplea una determinada lengua ${ }^{28}$. De ese modo, las palabras que designan los elementos de la naturaleza, las relaciones sociales y las creencias serán consecuencia del modo en que cada cultura ha interpretado esos ámbitos, mientras que la cultura material de una sociedad será fuente de palabras y expresiones que reflejarán algunos de los aspectos importantes de esa cultura. Un par de ejemplos muy simples lo demostrarán. Respecto de las relaciones sociales, es de sobra conocido que los términos de parentesco varían sustancialmente de unas lenguas a otras (hay lenguas en las que, v. g., se lexicaliza la oposición entre 'hermano mayor' y 'hermano menor', algo que no se da en español ni en las lenguas romances). Respecto del entorno material, el fuerte influjo del fútbol en la sociedad contemporánea, y en concreto en la española, es la fuente de la que han surgido expresiones tan comunes como Estar en fuera de juego 'estar desorientado', Tirar balones fuera o Casarse de penalti.

b) La abundancia de distinciones semánticas (vid. Cardona, 1976: 100-101; Casado Velarde, 1991: 68-69; Bernárdez, 2004: 124; Morant Marco y Díaz Rojo, 2005: 5-8; Morant Marco, 2005: 141). Es casi un tópico afirmar que los aspectos de la cultura (material o espiritual) de una comunidad que tienen una importancia destacada para la vida de sus individuos se convierten en focos de los que emanan distinciones léxicas con las que se afina la interpretación que la lengua hace de esos mismos ámbitos. Aquí podrían incluirse ejemplos tan conocidos como el de la nieve para la lengua inuí (si bien no son pocos los autores que han avisado de que este ejemplo suele exponerse tendenciosamente), la pasta para el italiano o las armas para el inglés estadounidense (Morant Marco, 2005: 141). Pero también es importante tener en cuenta que dentro de una lengua hay sectores concretos que generan esa misma abundancia de distinciones semánticas frente a lo codificado en la lengua general: baste con pensar en la riqueza de matices léxicos que para designar sus productos y actividades tiene el sector agrícola español en comparación con la lengua general ${ }^{29}$.

28 Como ya se ha afirmado en $\S 3$, aunque la naturaleza en sí misma es lo opuesto a la cultura, el modo en que esta se interpreta es un elemento cultural, dado que depende de cada comunidad humana.

29 Para el español común, un producto agrícola simplemente se "cultiva" (o, como mucho, se "siembra" y se "recolecta"), mientras que los agricultores tienen mucho cuidado a la hora de diferenciar las diversas fases y tareas de ese cultivo en función del producto concreto. Por ejemplo, en la comarca de La Vera (Cáceres), las labores del cultivo del tabaco incluyen, entre otras, acaballonar (hacer los caballones o surcos en los que se plantará el tabaco), poner (transplantar la planta de tabaco desde el semillero al surco para que crezca), binar (repasar los surcos con instrumentos o aparatos para quitar las malas hierbas), esyerbar (quitar a mano esas malas hierbas), curar (echar los pesticidas necesarios a la planta), destoñar (arrancar de la planta los toños, es decir, los retoños que impiden su buen crecimiento), descogollar (quitar de la planta las flores que la coronan para que no crezca más), aclarar (dejar los surcos limpios para que se pueda realizar la labor de repelar), repelar (en el caso del tabaco rubio, arrancar sus hojas por pisos, es decir, por niveles; si se trata de tabaco negro, la labor se llama deshojar y consiste en quitar a la planta todas las hojas una vez cortada), hacer bandejas (colocar las hojas en los aparejos en los que se secarán), secar (meter las hojas en hornos, o secaderos, para que adquieran la textura adecuada), seleccionar (clasificar las hojas de tabaco cuando se sacan del secadero en función de la textura alcanzada), enfardar (colocar las hojas secas en fardos para llevarlas al centro en el que se tratará el tabaco para elaborar los cigarrillos)... 
c) La evolución del léxico a partir de la evolución de la cultura (cfr. Casado Velarde, 1991: 73-75). Como toda disciplina lingüística, la etnolingüística puede adquirir también la perspectiva diacrónica, de modo que podrá abordar el estudio de cómo los cambios culturales repercuten en el léxico dando lugar a que aparezcan nuevas palabras y a que muchas otras se pierdan. Este fenómeno, no por obvio, resulta menos interesante, como también lo es que a menudo determinados objetos desaparezcan o se transformen radicalmente y sin embargo sigan presentes en la lengua con reminiscencias de su antigua forma: seguimos colgando el teléfono (cfr. Morant Marco y Díaz Rojo, 2005: 14), aunque haga tiempo que las conversaciones telefónicas finalizan aprentando un botón, tirando de la cisterna o de la cadena (cuando la mayoría de los cisternas de los inodoros funciona con un botón) o poniendo la sartén en el fuego aunque sea en una vitrocerámica o en una placa de inducción. En la misma línea se sitúa el hecho de que, a pesar de desaparecer el objeto, su nombre siga presente en unidades pluriverbales de plena vitalidad: colgar un sambenito, estar en la picota, no valer un real...

d) La ideologización de las palabras (cfr. Casado Velarde, 1991: 62-66), fenómeno de sobra conocido, cuadra perfectamente con el marco teórico de la etnolingüística, que puede mostrar no solo cómo la ideología, componente fundamental de la cultura, influye en las connotaciones y valores que adquieren las palabras, sino en las consecuencias que ello tiene en la vida social. Baste un ejemplo muy próximo: la disputa política surgida en los últimos tiempos, en España y en otros países, en torno a la unión legal entre personas del mismo sexo es, en gran medida, una discusión de raíz lingüística que gira en torno a la palabra matrimonio y a la interpretación connotativa que se le da desde distintos sectores ${ }^{30}$.

e) El léxico como reflejo de la visión del mundo de una sociedad. A menudo se ha afirmado que determinadas palabras reflejan aspectos muy íntimos de la mentalidad de una comunidad humana, llegando de ese modo a constituirse en símbolos de la "mentalidad nacional" (cfr. Casado Velarde, 1991: 69-72; Wierzbicka, 1997): el francés esprit, el español honra, el inglés privacy... Tal hecho es interesante, pero no hay que olvidar que un universal lingüístico es que todo contenido comunicable simbólicamente puede ser expresado en cualquier lengua (Moreno Cabrera, 2004: 65), por lo que el descubrimiento de palabras de este tipo debe entenderse solo como que la cultura correspondiente ha decidido dar una etiqueta a un concepto o noción que puede entenderse, y por tanto expresarse (aunque sea por medio de sintagmas o circunloquios), en cualquier lengua.

30 Obviamente, un trabajo de lingüística no es el lugar para debatir cuestiones de este tipo, pero sin duda es apasionante ver desde la óptica del estudioso del lenguaje cómo la base del problema -dejando aparte cuestiones morales y religiosas de otra índole- es fundamentalmente lingüística: llamar o no matrimonio a la unión entre personas del mismo sexo sobre todo por lo que esta palabra connota. De hecho, frente al problema connotativo, parece que la denotación sí "puede cambiarse" (si aceptáramos la ingenua idea de que los diccionarios sentencian y regulan el significado denotativo de las palabras): la última edición del DRAE ha añadido en la entrada matrimonio la acepción "En determinadas legislaciones, unión de dos personas del mismo sexo, concertada mediante ciertos ritos o formalidades legales, para establecer y mantener una comunidad de vida e intereses. 
f) Los nombres propios como portadores de huellas de la historia cultural (cfr. Cardona, 1976: 133-143; Casado Velarde, 1991: 83-85). Los topónimos y los antropónimos muchas veces responden a situaciones culturales históricamente determinadas, por lo que su estudio puede resultar interesante para conocer o corroborar lo que se sabe sobre la cultura que rodea o ha rodeado a una lengua. Baste con pensar en los múltiples topónimos relacionados con la religión católica que existen en España (vid. Casado Velarde, 1991: 85) o en la curiosa costumbre que se ha instaurado en los últimos años en nuestro país de buscar para los recién nacidos nombres lo más alejados posible a la tradición, algo que no deja de ser un índice de un cambio de mentalidad de un determinado sector de la población.

g) El tabú y el eufemismo (cfr. Cardona, 1976: 143-151), fenómenos ampliamente estudiados, tienen una raíz cultural obvia, de ahí que su estudio pueda ser perfectamente enfocado desde la etnolingüística, que podrá analizar, entre otras cuestiones, qué realidades y objetos convierte en tabú una lengua según su cultura y a qué ámbitos y referentes culturales recurre para encontrar los correspondientes eufemismos (y disfemismos).

h) El estudio de las etimologías de las palabras puede servir para descubrir datos interesantes de las culturas que han ido asociándose a una lengua, tanto a nivel general (por ejemplo, la abundancia de arabismos en español [Lapesa, 1981: 133-140] demuestra que la Reconquista no fue una guerra de 800 años, ya que durante ese periodo de tiempo hubo entre cristianos y árabes contactos culturales continuados y fructíferos), como a nivel particular, dado que la etimología de una palabra puede descubrir hechos culturales del pasado ${ }^{31}$.

i) De modo similar, el análisis de los extranjerismos que recibe una lengua puede constituir una fuente de conocimiento de las relaciones interculturales que establece la sociedad que la emplea, tanto a nivel sincrónico como a nivel diacrónico. A nivel sincrónico, está claro por ejemplo que el español -como muchas otras lenguas- recibe actualmente un incesante caudal de anglicismos, algo que demuestra por sí solo el influjo de las culturas anglosajona y estadounidense sobre la española; pero a nivel más concreto, puede observarse que en determinados campos se producen influjos de otras culturas, como sería el caso, v.g., de la francesa en el ámbito de la moda (chic, pasarela, glamour, bisutería...) o de la gastronomía (baguette, croissant, bechamel, paupieta...). A nivel diacrónico, basta con investigar en las historias de la lengua para percibir cómo el número y la procedencia de los extranjerismos que ha ido recibiendo una lengua a lo largo de su historia son un claro índice de las relaciones culturales que la sociedad correspondiente ha establecido con otras: en el caso del español, de los galicismos medievales se pasó a los italianismos en el Renacimiento y en el Siglo de Oro; de estos de nuevo a los galicismos en los siglos XVIII y XIX; y a partir del XIX empezó el citado aluvión de anglicismos, términos que antes prácticamente no habían entrado en el idioma (cfr. Lapesa, 1984: 199-200, 409-410, 454-460).

31 Vid. los ejemplos mencionados por Casado Velarde (1991: 79-80), quien explica la etimología de palabras como linchar o moneda. Cierto es que este estudio individual de la etimología puede llevar a lo anecdótico (como de hecho se revela en el propio título del libro de Doval Palabras con historia. Etimología razonada y anecdótica de palabras con origen curioso), pero no por ello hay que despreciarlo. 
j) La influencia de las palabras sobre el pensamiento. Como se sabe, el hecho de que la lengua se conecte con la cultura y de que esta incluya la cosmovisión de la sociedad correspondiente determinó una línea de pensamiento (iniciada por Humboldt) que culminaría con la conocida como "hipótesis Sapir-Whorf”, según la cual esa carga cultural de la lengua no solo reflejaría el modo en que los hablantes interpretan la realidad, sino que incluso la determinaría. No es este el lugar para entrar en detalles sobre esta hipótesis ${ }^{32}$, pero sí queremos llamar la atención sobre un hecho que apenas se ha investigado aunque está en las tesis del propio Whorf (en especial, en Whorf, 1941: 125-128): el influjo que ejerce la lengua sobre el pensamiento no solo se cumpliría en la gramática (cfr. § 5.2), sino también en las palabras. Estas, como muy acertadamente y con profusión de ejemplos demuestra Álex Grijelmo (2000), pueden ejercer diversos influjos sobre el pensamiento de los receptores y, por ende, sobre su percepción de la realidad, debido a la carga de connotaciones, valores emotivos y asociaciones que la cultura ha depositado en ellas ${ }^{33}$. Se trata, por tanto, de un campo de trabajo que puede dar frutos muy interesantes y que demostraría que la conexión del léxico con la cultura no se limita a proporcionar datos curiosos o anecdóticos.

k) Finalmente, se puede aludir al papel que la cultura tiene en la conformación del discurso repetido, ámbito que ofrece varias líneas de trabajo. Por un lado, hay que tener en cuenta que la categorización de la realidad se hace a menudo a partir de unidades de discurso repetido que permiten presentarla de forma metafórica; este tema, cuyo tratamiento se inició probablemente con la célebre obra de Lakoff y Johnson (1980) y ha sido continuado profusamente por la lingüística cognitiva (vid. Bernárdez, 2004: 253-255), puede ser abordado desde la etnolingüística para mostrar que esas unidades de discurso repetido que conceptualizan metafóricamente la realidad tienen a menudo una raíz cultural. Por otro lado, estos elementos pluriverbales muestran con frecuencia el influjo de determinados ámbitos culturales de especial relevancia en una sociedad (cfr. Casado Velarde, 1991: 82-83), como son, v.g., la religión (vid. los ejemplos presentados al inicio de esta sección), la tauromaquia (ídem) o la economía (valer [alguien] un tesoro, no importar un real, ser [alguien] una joya, iQue te den dos duros!...). En ocasiones, esa influencia puede proceder, incluso, de un solo objeto o concepto, algo que demuestra la importancia que este tiene o ha tenido en una determinada sociedad ${ }^{34}$.

32 La bibliografía al respecto es abundante. Para nuestras intenciones, basta citar aquí la interesante exposición que hace del tema Casado Velarde (1991, 53-57) y la lectura imprescindible de Lucy (1992).

33 No nos detendremos a exponer ejemplos porque ello exigiría mucho desarrollo. Invitamos a leer el interesante libro de Grijelmo, donde se encontrarán suficientes muestras de lo expuesto.

34 Ejemplo paradigmático de ello es el caso del vino en español, concepto que ha originado unidades como $A$ buen vino, buen tocino; A buen vino, no hay mal bebedor; A nadie le hace daño el vino, si se toma con tino; De las uvas sale el vino y del vino el desatino y un largo etcétera (cfr. la relación presentada en www.refranerocastellano. com, donde se registran más de 250 refranes en los que aparece la palabra). 


\subsection{El estudio etnolingüístico de la gramática}

Frente a la profunda influencia que sobre el léxico ejerce la cultura, la que se cumple sobre la gramática es de menor calado y, probablemente, se limita a aspectos periféricos como puede ser, por ejemplo, el género ${ }^{35}$.

Por tal razón, el estudio de esta relación debe abordarse con sumo cuidado, sin dejarse llevar por apreciaciones superficiales que induzcan a establecer asociaciones entre gramática y cultura que no estén justificadas. Al respecto, J. Tusón (apud Morant Marco y Díaz Rojo, 2005: 7) plantea un ejemplo clarificador: sería ingenuo afirmar que "son las tres menos veinticinco" y "son los dos y treinta y cinco", a pesar de coincidir en su valor referencial, representan diversas formas de entender el mundo porque el primer enunciado transmite una especie de interpretación de la realidad basada en lo futuro y el segundo una interpretación basada en lo pasado. En cambio, Bernárdez (2004: 255-259) afirma que el influjo de la gramática es mayor de lo que suele afirmarse, algo que ilustra con ejemplos interesantes (la costumbre de ciertas lenguas de no expresar el agente más que en casos muy concretos, la existencia de distintos tipos de pasado en muchas lenguas...). No obstante, como él mismo reconoce, su intención al presentar estos fenómenos no es afirmar que "dependan exclusivamente de factores culturales, ni siquiera principalmente de ellos", ya que "en numerosas lenguas, la gramática está tan institucionalizada que casi todo está determinado a priori” (ídem: 258).

En todo caso, hay aspectos gramaticales en los que el papel de la cultura es innegable. Se presentarán algunos casos representativos:

a) La evolución de la cultura no solo influye en el léxico (cfr. § 5.1), sino también en diversos hechos gramaticales (vid. Casado Velarde, 1991: 73-74). Así, en español se documentan casos como el de la creación del futuro romance (amare habeo, frente al sintético amabo del latín clásico) por influencia de la nueva mentalidad cristiana o, en la actualidad, el de la evolución de los nombres de profesiones, que van adquiriendo progresivamente la forma femenina gracias a los cambios de mentalidad y de situación de la mujer dentro de la sociedad ${ }^{36}$.

35 La afirmación de que el género es un aspecto periférico de la gramática se refiere a que su relevancia para la construcción estructural de los enunciados es solo superficial, como de hecho lo demuestra el que no se encuentre, desde el punto de vista formal, en muchas de las lenguas del mundo. Obviamente, el género puede tener un papel importante en la lengua y en la interpretación que esta hace de la realidad, de ahí que precisamente sea uno de los aspectos de la gramática en los que se observa la influencia de la cultura.

36 No deja de ser llamativo que, si bien las obras normativas sentencian formas como médica o jueza, se perciba una resistencia a su uso que no siempre es fácil de explicar. Cierto es que, como señala Casado Velarde (1981: 74), hay algunas razones, indudablemente culturales, que explican tal situación, entre ellas que en un pasado no muy remoto el femenino de las profesiones no designara otra cosa que la 'esposa del' (boticaria, coronela...). Sin embargo, a pesar de esas justificaciones siguen existiendo casos de mujeres que rechazan el empleo del femenino para su profesión por motivos que deberían investigarse con mayor detenimiento, ya que son índices de situaciones culturales que merece la pena analizar. Nos referimos por ejemplo a la extendida costumbre de colocar en los carteles identificativos la forma masculina de la profesión a pesar de que sea ejercida por una mujer: Aurora $X X$, abogado; administrador de fincas (el ejemplo, mutatis mutandis, es real y lo hemos encontrado en una calle de nuestra ciudad). 
b) Un tipo de elemento gramatical que presenta a menudo conexiones con la cultura son los clasificadores ${ }^{37}$, si bien esas conexiones no siempre son visibles para los hablantes: como ya se ha comentado (vid. nota 25), Palmer atribuye a las creencias espirituales de la etnia bantú los catorce clasificadores que emplean sus lenguas para distinguir los sustantivos. De modo similar, el uso del género en español (aunque seguramente este no pueda considerarse un clasificador en el sentido estricto del término) tiene en ciertos casos una raíz cultural; de hecho, el género de las palabras españolas se explica por varias causas ${ }^{38}$ :

- Etimológicas: el sustantivo conserva el género de su antecesor latino. Es lo más habitual, aunque hay numerosas excepciones, algunas debidas a los factores que se relacionan seguidamente.

- Formales: el género está determinado por la frecuencia con que la oposición -o / - $a$ actúa como marca morfémica de esta categoría. Por ejemplo, faro es femenino en latín pero masculino en español posiblemente por su terminación en - $o$.

- Lingüísticas: asociaciones sintagmáticas o paradigmáticas, el empleo de determinados sufijos y otros fenómenos similares condicionan la asignación de género a muchos sustantivos. Por ej., llamamiento es masculino por el simple hecho de que el sufijo - $m$ (i)ento produce siempre tal resultado.

- Motivaciones internas: en las palabras con moción genérica, esta refleja una distinción sexual (maestro / maestra, gato / gato) o de tamaño (cubo / cuba, mazo / maza o ramo / rama $)^{39}$.

- Motivaciones externas en las que es posible ver diversas relaciones entre el género y factores culturales. Así, ocurre que muchas palabras adquieren su género por la asociación con elementos que se constituyen en patrones o modelos de la cultura correspondiente: segadora se asocia a "máquina", mientras que secador a "aparato"; ayuntamiento, parlamento o senado son "organismos"... De igual modo, ocurre en ocasiones que el género refleja aspectos de la cultura espiritual: la mitología grecolatina identificaba numerosas realidades físicas o espirituales

37 Los clasificadores son morfemas o palabras que, añadidos a un sustantivo o a un sintagma nominal, indican su pertenencia a una determinada clase en función de las características que se perciben en ellos o de las que se les atribuyen. En las lenguas en que aparecen, actúan de forma sistemática, de modo que todo sustantivo o sintagma debe ir acompañado de su clasificador correspondiente (cfr. Marco, 1988: 5-7; Palmer, 2000: 157-158).

38 Esta exposición no pretende presentar la solución a un problema que lleva siglos ocupando a los estudiosos del español y a los lingüistas en general. La distribución del género en español -como sucede en las demás lenguas indoeuropeas que poseen tal categoría- es bastante desconcertante y arbitraria, por lo que los datos expuestos deben tomarse como una propuesta de explicación muy simplificada e interesada solo en resaltar la conexión que el género puede establecer con la cultura.

39 Se ha afirmado que este empleo del género para establecer distinciones de tamaño se fundamenta en un planteamiento animístico que atribuiría a lo femenino la amplitud, la profundidad y la fecundidad, ausentes en lo masculino. Sin necesidad de llegar a tal extremo, parece posible considerar que en este caso ha actuado un determinado componente de la visión del mundo que asociaría lo grande con lo femenino y lo pequeño con lo masculino. Obviamente, hay excepciones a esta pauta, como río / ría, barco / barca (que quizás tengan su explicación en cuestiones formales o culturales) y, sobre todo, las parejas árbol / fruto, aunque esta última excepción es más sencilla de explicar: en latín los nombres de los árboles solían ser femeninos en -um y los frutos -también de la segunda declinación en - um-, neutros, lo cual cuadra con la hipótesis que relaciona el femenino con lo grande y el masculino con lo pequeño. Sin embargo, en español cambió la distribución por razones formales y etimológicas: el paso -um > -o hizo que los árboles tomaran género masculino; mientras que los nombres de los frutos, al proceder del plural en $-a$, se hicieron femeninos. 
con deidades masculinas y femeninas, de modo que, por ejemplo, los géneros de la Tierra, el Sol y la Luna corresponden a divinidades de esos mismos géneros (Gea y Tellus, Selene y Febe eran diosas y representaban a la tierra y a la luna; Helio y Apolo eran los dioses del sol).

c) El influjo de la cultura se siente también a veces en la morfología derivativa, dado que no es infrecuente que determinados afijos aparezcan, o incluso desaparezcan, por razones culturales. Como es bien sabido, el sufijo -mente surgió en latín tardío (de donde llegó al español y a otras lenguas romances) por el cambio de mentalidad ocasionado por la expansión del cristianismo, que favoreció la fijación como morfema de la forma mente que en su origen era parte de una construcción de ablativo. Del mismo modo, actualmente ha surgido en español, o está en vías de aparición, un sufijo -ing que, a partir de las muchas palabras del inglés en las que se presenta y que se han difundido notablemente en la cultura española por el fuerte influjo de la estadounidense (mobbing, spinning, rafting, leasing, doping, renting, lifting...), se asocia ya a bases españolas para formar palabras de lo más variado, como puenting 'saltar desde un puente sujeto a una cuerda elástica', vending 'sistema de venta por medio de máquinas expendedoras', edredoning 'tener relaciones sexuales debajo de un edredón', balconing 'saltar desde un balcón a la piscina', bicing 'transporte público en bicicleta', aceituning ${ }^{40} \ldots$

d) Finalmente, sería este ámbito el que podría acoger los estudios sobre el relativismo lingüístico y su manifestación en la ya citada hipótesis Sapir-Whorf. Como se ha mencionado, esta hipótesis ha sido muy estudiada y debatida, por lo que no parece este el lugar para volver sobre ella. Para nosotros resulta suficiente la adhesión a las dudas, expresadas por diversos estudiosos (cfr. Casado Velarde, 1991: 55-57), sobre la posibilidad de que sea la gramática la que puede influir en la visión del mundo de los hablantes; más bien creemos, como se ha mencionado en $\S 5.1$, que esa influencia pueden ejercerla las palabras.

\subsection{El estudio etnolingüístico de la fonología}

La posible influencia de la cultura sobre aspectos relacionados con la pronunciación de la lengua es un campo todavía casi inexplorado. De hecho, son pocos los fenómenos que podrían incluirse en este ámbito de forma indudable, ya que mientras que algunos parecen más bien objeto de estudio de la sociolingüística, en otros queda por demostrar que exista un verdadero influjo de la cultura.

En la primera situación se encuentran, por ejemplo, hechos como la adopción por parte del hablante de un determinado tipo de pronunciación (v.g., la de su dialecto frente a la norma estándar) en función de su deseo de establecer una relación de convergencia o de divergencia respecto de su interlocutor (cfr. Moreno Fernández, 1998: 155, 247-250), algo que, a pesar de tener relación con aspectos culturales (en concreto, con actitudes, creencias e ideologías), cae dentro del foco de interés de la sociolingüística.

40 Esta forma es el nombre que se le ha dado a una reciente campaña publicitaria, apoyada por el Ministerio de Agricultura, para promover el consumo de aceitunas aliñadas. Ver www.elaceituning.es, donde se da la siguiente definición: "El aceituning es un nuevo concepto culinario que consiste en enriquecer las aceitunas envasadas que puedes encontrar en cualquier establecimiento mediante originales aliños." 
Semejante es el caso de los rasgos articulatorios y entonativos que caracterizan las hablas de ciertas subculturas, como la pronunciación afectada de determinados grupos socioeconómicos o, en el extremo contrario, la intencionalmente descuidada de lo que a finales del siglo XX se llamó "habla pasota". Tales lectos son, como se mostrará en $\S 5.5$, objeto de estudio de la etnolingüística, si bien es cierto que podrían ser analizados también por la sociolingüística.

La segunda situación es la que ejemplica el fenómeno del fonosimbolismo. Diversos autores (por ejemplo, Palmer, 2000: 319-330; Morant Marco y Díaz Rojo, 2005: 15-16) han afirmado que las onomatopeyas y los valores subjetivos que se asocian con determinados fonemas tienen una raíz cultural. Así, Morant Marco y Díaz Rojo mencionan el caso del fonema $/ \mathrm{t} \square /$, que tiene valores despectivos (populacho, mamarracho...) pero también afectivos (Chechu, Nacho...), dualidad que demostraría que dichos valores no son intrínsecos al fonema sino adquiridos por la cultura en contextos concretos. Del mismo modo, Grijelmo (2000: 37-58) presenta toda una red de asociaciones de muchos de los fonemas españoles con diversas nociones o sentimientos; por ejemplo, la vocal /a/ con la blancura y la candidez, o la consonante / $\mathrm{r}$ / con la energía y la fuerza. La realidad de esas asociaciones entre fonemas y valores subjetivos parece fuera de duda, pero a nuestro juicio queda por demostrar si están determinadas psicológica o culturalmente, $\mathrm{y}$, si es este último el caso, cuáles pueden ser las razones culturales de este tipo de asociaciones.

\subsection{El estudio etnolingüístico del discurso}

En la definición que este trabajo propone para la etnolingüística se afirma explícitamente que esta debe interesarse también por el estudio de la repercusión que tiene la cultura sobre el uso efectivo del lenguaje en la comunicación, esto es, sobre los discursos ${ }^{41}$. Ahora bien, este interés de la etnolingüística por el empleo comunicativo de la lengua la lleva a confluir con la pragmática, con el análisis del discurso y con el análisis de la conversación, de modo que se hace necesario definir su papel en este ámbito como complementario pero a la vez independiente de estas disciplinas. Complementario porque sus investigaciones pueden enriquecer las nociones aportadas por los estudios de la pragmática, del análisis del discurso y del análisis de la conversación (cfr. § 4.4). Independiente porque en su investigación de los fenómenos comunicativos la etnolingüística no debe usurpar temas de estudio o conceptos que no le competan, de modo que, al menos en nuestra opinión, no debe entrar en el debate teórico sobre nociones (acto de habla, cortesía, acto indirecto, implicatura, turno...) que solo le interesan como medio, no como fin.

Partiendo de ahí, el elenco de temas sobre los que la etnolingüística puede investigar en este ámbito es bastante amplio. Se comentarán los que parecen más interesantes:

a) El estudio de la influencia ejercida por la cultura en la tipología de géneros discursivos existentes en cada lengua y, en especial, del modo en que se configuran los que presentan manifestaciones concretas en función de la cultura. En ese sentido, y dicho de forma provisional dado que hay pocos estudios sobre el asunto (cfr. Car-

41 Empleamos "discurso" en un sentido genérico para aludir a cualquier manifestación concreta del uso de la lengua, sea interactiva o no. Por tanto, con esta noción se engloba lo que según las corrientes y estudiosos se denominan "acto de habla", "texto (oral / escrito)", "conversación", "interacción comunicativa" y, cómo no, "discurso". 
dona, 1976: 213-236, donde hay observaciones y referencias interesantes), parecen relevantes para el estudio etnolingüístico los géneros discursivos propios de cada sociedad o al menos no universales por un lado, y la forma en que se manifiestan y funcionan dentro de una sociedad determinados géneros especialmente influidos por la cultura, por el otro. Por supuesto, el primer ámbito es el más difícil de abordar, pero sería interesante saber si todas las lenguas tienen o no, por ejemplo, un género discursivo similar a lo que en occidente se conoce como "chiste". En el segundo entraría el estudio de manifestaciones comunicativas en apariencia universales (o al menos muy difundidas) y que sin duda están muy condicionadas por la cultura, como los saludos, los insultos, los juegos lingüísticos o las fórmulas rituales ${ }^{42}$.

b) La competencia comunicativa presenta, evidementemente, una vertiente cultural intrínseca. De las varias descripciones de este concepto (por ejemplo, Hymes, 1971; Canale, 1983; Coseriu, 1994; Moreno Fernández, 1998: 203-206), partiremos de la de Canale, quien considera que esta competencia tiene cuatro subcomponentes: gramatical, discursivo, estratégico y sociolingüístico. Este último alude -a pesar de su nombre- a fenómenos que caen de lleno dentro del ámbito de interés de la etnolingüística, pues define el conocimiento que debe tener el hablante de una serie de reglas socioculturales que le indicarán cómo debe usar la lengua en cada situación, adecuando a ella los enunciados concretos. Tales reglas, como es fácil de entender, son propias de cada cultura (e, incluso, dentro de una misma sociedad, de las distintas costumbres, creencias o pautas de comportamiento de cada grupo concreto), de tal manera que aspectos como el uso de los estilos en función del tema, la elección de las formas de tratamiento dependiendo de los interlocutores, el uso o no de ciertas palabras o expresiones según el tema del intercambio comunicativo, y muchos otros elementos, no serán universales, sino que dependerán de cada cultura concreta. Ello, obviamente, abre un campo de estudio inmenso, sobre todo desde el punto de vista comparativo.

c) Los modos en los que se construyen los intercambios comunicativos en general, y las conversaciones en concreto, muestran también una faceta cultural innegable ${ }^{43}$. En ese sentido, la etnolingüística puede contribuir a lo estudiado por otras disciplinas

\footnotetext{
42 Por ejemplo, en el español peninsular se observa una clara influencia cultural sobre los saludos, que en pocos años han pasado de los tradicionales hola, adiós, con Dios, buenos días... a fórmulas en las que se observa un claro cambio de mentalidad, como son buenas, hey, vamos, nos vemos, chao... Por otro lado, parece estar difundida la idea de que las fórmulas rituales son propias de comunidades para nosotros exóticas, en las que es un chamán el que las emplea para invocar a los espíritus; sin embargo, fórmulas de este tipo existen también en lenguas como el español, donde se emplean (o empleaban), a veces con cierto humor, para los más variados fines, algo que trasluce la influencia que la religión cristiana ha tenido tradicionalmente en la sociedad española: para pedir por los resultados de los exámenes se emplea(ba) el conocido Virgen santa, Virgen pura, que apruebe esta asignatura; y en esa línea existen oraciones para encontrar pareja (dirigida a San Antonio de Padua), para alcanzar favores casi imposibles (a San Judas Tadeo), para conseguir ayuda urgente (a San Expedito), etc. Finalmente, por poner un ejemplo más, el campo de los insultos es muy interesante, pues los que se codifican varían mucho de una lengua a otra y tienen claros valores culturales: v. g., el insulto español hijo de puta tiene muchos usos, pues no solo significa lo que trasmite su valor literal, sino que sirve para insultar a cualquier persona o incluso animal o cosa que al hablante le enfade especialmente, de modo que no tiene una equivalencia única en otras lenguas.

43 Sobre cómo influye la cultura en la forma de organizar los intercambios comunicativos, vid. las interesantes reflexiones de Palmer (2000: 205-223). Por otro lado, aunque no entramos aquí en discusiones teóricas al respecto (cfr. Tusón Valls, 1997: 14-15, 67-72), consideramos la conversación como un tipo concreto de intercambio comunicativo, ya que hay otras modalidades comunicativas que, a pesar de ser interactivas, no se ajustan a sus pautas (un debate, una entrevista, un interrogatorio...).
} 
analizando el influjo que la cultura ejerce sobre dos ámbitos. Por un lado, sobre la forma en la que se organiza la conversación en una determinada cultura, pues aunque las nociones de turno y de alternancia de turno (y otras adyacentes) seguramente sean universales, el modo en que se manifiestan en cada cultura puede variar de forma notable, como bien argumenta Duranti (2000: 329-375) ${ }^{44}$. Por otro, sobre el catálogo de formas interactivas no conversacionales propias de cada comunidad, ya que muchas de estas nacerán seguramente de prácticas culturales individuales o, al menos, restringidas a determinados conjuntos de sociedades.

d) Los actos de habla concretos tienen también una vertiente cultural, pues aunque muchos de ellos puedan aparecer de forma (casi) universal, su interpretación, valor y forma concreta de manifestarse pueden variar de una cultura a otra. En esa línea, sería interesante analizar si los actos de habla que suelen señalarse son universales en sí mismos (¿se miente en todas lenguas?) y cómo se conforman en función de la cultura (¿cómo se miente en español a diferencia de otras lenguas?) ${ }^{45}$.

e) Muy relacionado con lo anterior, la etnolingüística puede abordar el estudio de los actos de habla indirectos, pues hay claros indicios de que su tipología y los mecanismos que se emplean para activarlos varían de unas comunidades a otras (cfr. lo dicho en $\S 4.3)$.

f) Finalmente, puede aludirse a la importancia que tiene el conocimiento del contexto cultural para la construcción y comprensión de los mensajes concretos. Para comunicarse adecuadamente, tanto emisor como receptor deben conocer las costumbres, las creencias, los modos de interrelación social y las formas de entender el mundo de cada comunidad, dado que ello determina en gran medida qué se dice (o qué no, bien porque sea tabú o inadecuado, bien porque se dé por sobreentendido) y cómo se dice. Unos ejemplos muy simples servirán como ilustración: qué es tabú para los hablantes de una lengua puede no serlo en absoluto para los de otra; el ofrecimiento que se hace en español de decirle a alguien Toma lo que quieras; estás en tu casa es muy difícil de comprender para muchos hablantes de otras lenguas; como les es también complicado de entender que en ciertos ámbitos y situaciones en España haya quien se salude con insultos.

\subsection{El estudio etnolingüístico de otros aspectos del lenguaje}

Finalmente, y a modo de miscelánea, se presentarán otros ámbitos lingüísticos que reflejan la repercusión de la cultura y que, por consiguiente, pueden convertirse en objeto de estudio de la etnolingüística.

a) En primer lugar, determinadas variedades lingüísticas, en especial los argots, esto es, las variedades de una lengua caracterizadas por su intención críptica y su empleo por parte de grupos sociales marginales (vid. Rodríguez Díez, 1981: 53),

44 Entre los aspectos en los que se perciben diferencias culturales cabe destacar el empleo de los recursos que sirven para guiar los cambios de turno (fórmulas lingüísticas, uso del silencio, gestos...), la duración prototípica de los turnos o las consecuencias que acarrea el solapamiento de los turnos.

45 Hemos elegido el ejemplo de la mentira basándonos en la interesante exposición que hace de ella Palmer (2000: 231-237). 
suelen nacer de lo que se suele denominar contracultura, de modo que toda su conformación, desde su léxico a sus unidades de discurso repetido, puede relacionarse con el influjo que ejerce ese pensamiento opuesto a la cultura dominante (vid. como ejemplo la exposición que se presenta del argot juvenil en Casado Velarde, 1991: 101-110).

b) Pero no solo las variedades lingüísticas pueden ser estudiadas en su conjunto desde el enfoque de la etnolingüística. Incluso, se podría abordar, aunque esto sería materia de una investigación muy amplia, el estudio etnolingüístico de toda una lengua, tanto desde el punto de vista sincrónico como desde el diacrónico. Desde una perspectiva sincrónica, habría que delimitar los aspectos más importantes de la cultura de una sociedad para ver cómo estos se manifiestan en todos los niveles de esa lengua ${ }^{46}$. Desde un enfoque diacrónico, sería interesante analizar cómo los principales cambios ocurridos en la cultura han ido modificando el aspecto (léxico y en algunos casos gramatical) de una determinada lengua.

c) Por último, sería posible abordar el estudio de la comunicación no verbal (cinésica, proxémica y paralenguaje) desde el punto de vista de la etnolingüística, pues es obvio que los gestos y movimientos, el uso de las distancias, y las vocalizaciones que acompañan a los actos lingüísticos suelen variar de una lengua a otra en función de la cultura subyacente ${ }^{47}$.

\section{Conclusiones}

Este artículo ha intentado combinar la reflexión teórica sobre diversas fuentes bibliográficas con el análisis de muy diversos hechos y datos lingüísticos para proponer un esbozo de caracterización global de una disciplina casi olvidada, tanto en los manuales de lingüística como en la docencia y en la investigación sobre el lenguaje, a pesar de que, como se ha procurado mostrar con diversos argumentos y con suficientes ilustraciones, posee un campo de trabajo propio, concretado en muy variados temas de estudio que se asocian con cada uno de los niveles lingüísticos y que no se limitan a tratar cuestiones puramente anecdóticas o superfluas.

Partiendo de ese presupuesto, se ha definido la etnolingüística como una disciplina interesada por estudiar cómo la cultura -entendida en sentido lato como todo aquello que el ser humano crea al actuar física o mentalmente sobre la naturaleza- ejerce una indudable influencia sobre la lengua, tanto al nivel del sistema como al nivel de su uso efectivo en la comunicación, influencia que tiene como consecuencia directa que los propios elementos lingüísticos se conviertan en portadores de huellas de esa misma cultura.

Tal definición podría ser tachada de imprecisa o de ser demasiado general, de ahí que se haya abordado su desarrollo y concreción por dos vías.

46 Obviamente, este objetivo es muy difícil de alcanzar en el caso de lenguas asociadas a culturas muy diversificadas, algo que explica que la antropología lingüística haya abordado estudios de este tipo pero referidos siempre a lenguas de comunidades restringidas y de cultura uniforme.

47 Así lo hacen Cardona (1976: 169-174) y, con algunas alusiones, Morant Marco y Díaz Rojo (2005: 16-17). Como se señala en estas fuentes, aunque algunos gestos o vocalizaciones parecen ser universales, la mayor parte de ellos se conforman de modos distintos según las culturas. 
En primer lugar, ubicando la etnolingüística dentro del panorama de la lingüística general, algo que ha permitido ver sus conexiones con otras disciplinas (pragmática, análisis del discurso y análisis de la conversación) y, en especial, deslindarla de la sociolingüística (con la que comparte ámbito de interés debido a la simbiosis que existe entre sociedad y cultura, pero no temas de estudio) y, sobre todo, de la antropología lingüstica, disciplina que, a pesar de encontrarse muy relacionada con la etnolingüística por su campo de interés y por sus temas de estudio, se encuadra en un marco epistemológico y metodológico totalmente distinto (la etnolingüística es una de las ramas de la lingüística externa; la antropología lingüística, una de las vertientes de la antropología general).

En segundo lugar, señalando los ámbitos en que se manifiesta la relación de la cultura con los hechos lingüísticos (léxico, gramática, fonología y fonética, y uso efectivo de la lengua) y haciendo un repaso, no exhaustivo, de los diversos campos y temas concretos que puede estudiar esta disciplina, desde el influjo que la cultura ejerce sobre la conformación del vocabulario de una lengua a la que tiene sobre la organización de los intercambios comunicativos.

Todo ello lleva a concluir que, si se la quiere aceptar en el mundo de las ciencias del lenguaje, la etnolingüística puede presentarse como una disciplina mucho más atrayente y fructífera de lo que podría hacer pensar su abandono, pues sus campos de trabajos son variados y conectan muchas veces con cuestiones fundamentales del comportamiento lingüístico. $\mathrm{Y}$ es que no hay que olvidar $-\mathrm{y}$ ello es un argumento a favor del respeto hacia las lenguas $\mathrm{y}$, por tanto, un buen antídoto contra los prejuicios lingüísticos- que toda lengua se asocia con una cultura que no solo la influye en aspectos anecdóticos, sino que da cuenta de por qué la lengua es como es y se usa como se usa en muchos de sus aspectos idiosincrásicos.

\section{Referencias bibliográficas}

Alcaraz Varó, E. y Martínez Linares, Mà . A. (2004²): Diccionario de lingüística moderna. Barcelona, Ariel. Amorós Negre, C. (2014): Las lenguas en la sociedad. Madrid, Síntesis.

Appel, R. y Muysken, P. (1996): Bilingüismo y contacto de lenguas. Barcelona, Ariel.

Ariza Viguera, M. (2001): "Sexo, religión y política en el diccionario de la Real Academia", Interlingüistica, 11, págs. 11-26.

Baldinger, K. (1985): "Lengua y cultura: su relación en la lingüística histórica", Revista de la Sociedad Española de Lingüistica, 15/2, págs. 247-276.

Bernárdez, E. (2004): ¿Qué son las lenguas? Madrid, Alianza.

Calsamiglia Blacafort, H. y Tusón Valls, A. (1999): Las cosas del decir. Barcelona, Ariel.

Canale, M. (1983). «De la competencia comunicativa a la pedagogía comunicativa del lenguaje». En Llobera et al. (1995): Competencia comunicativa. Documentos básicos en la enseñanza de lenguas extranjeras. Madrid, Edelsa, págs. 63-83.

Cardona, G. (1976): Introduzione all'etnolinguistica. Bologna, Il Mulino.

Casado Velarde, M. (1991): Lenguaje y cultura. La etnolingüística. Madrid, Síntesis.

Černý, J. (1998): Historia de la lingüística. Cáceres, Universidad de Extremadura.

Coseriu, E. (1977): "Introducción al estudio estructural del léxico". En Principios de semántica estructural. Madrid, Gredos, págs. 87-142.

Coseriu, E. (1978): Gramática, semántica, universales. Madrid, Gredos.

Coseriu, E. (1981): "La socio- y la etnolingüística. Sus fundamentos y tareas", Anuario de letras, XIX, págs. 5-30.

Coseriu, E. (1994): Competencia lingüistica. Elementos de la teoría del hablar. Madrid, Gredos. 
Crystal, D. (1991): The Cambridge Encyclopedia of Language. Cambridge, Cambridge University Press. Díaz Rojo, J. A. (2002): “Aspectos etnolingüísticos de la palabra sangre”. En Serra Alegre, E. et al. (eds.): Panorama de la investigació lingüistica a l'Estat espanyol. Actes del I Congrés de Lingüística General. València, Universitat de València, págs. 19-29.

Doval, G. (2002): Palabras con historia. Etimología razonada y anecdótica de palabras con origen curioso. Madrid, Ediciones del Prado.

Duranti, A. (1992): "La etnografía del habla: hacia una lingüística de la praxis". En Newmeyer, F. (coord.): Panorama de la lingüistica moderna de la Universidad de Cambridge IV. El lenguaje: contexto socio-cultural. Madrid, Visor, págs. 253-273.

Duranti, A. (2000): Antropología lingüistica. Madrid, Cambridge University Press.

Duranti, A. (ed.) (2001): Linguistic Antrophology. A Reader. Malden, Blackwell.

Escandell Vidal, $\mathrm{M}^{\mathrm{a}}$. V. (1996): Introducción a la pragmática. Barcelona, Ariel.

Fernández, Ma . del R. y Hachén, R. R. (1995): “¿De qué hablamos cuando hablamos de etnolingüística?", Revista de la Escuela de Antropología, 3, págs. 1-4.

Fernández Guizzetti, G. (1957): "La etnolingüística: del mundo del idioma al mundo de la cultura", Revista de Antropología, 5/1, págs. 75-93.

Fernández Pérez, M. (1986): “Las disciplinas lingüísticas”, Verba, 13, págs. 15-73.

Fernández Pérez, M. (1999): Introducción a la lingüística. Barcelona, Ariel.

García Marcos, F. (1999): Fundamentos críticos de sociolingüística. Almería, Universidad de Almería.

García-Page, M. (2004): "De los fines y confines de la fraseología". En González Calvo, J. M. et al. (eds.): VII Jornadas de Metodología y Didáctica de la Lengua Española. Las unidades fraseológicas. Cáceres, UEX, págs. 23-79.

Garvin, P. L. y Lastra de Suárez, Y. (1974): Antología de estudios de etnolingüística y sociolingüistica. México, UNAM.

Giles, H. y Byrne, J. L. (1981): "Aproximacion intercomunitaria a la adquisicion de la segunda lengua”, Revista de Educación, 29-268, págs. 77-102.

Grijelmo, Á. (2000): La seducción de las palabras. Madrid, Santillana.

Gutiérrez Ordóñez, S. (2002): "Nuevos caminos en la lingüística (aspectos de la competencia comunicativa)". En De pragmática y semántica. Madrid, Síntesis, págs. 79-128.

Hymes, D. (1964): "Hacia etnografías de la comunicación". En Garvin, P. L. y Lastra de Suárez, Y. (eds.) (1974): Antología de estudios de etnolingüística y sociolingüistica. México, UNAM, págs. 48-89.

Hymes, D. (1971): “On Communicative Competence”. En Duranti, A. (ed.): Linguistic Antrophology. A Reader. Malden, Blackwell, 2001, págs. 53-73.

Lakoff, G. y Johnson, M. (1980): Metaphors We Live By. Versión española: Metáforas de la vida cotidiana. Madrid, Cátedra, 1991.

Lapesa, R. (19819): Historia de la lengua española. Madrid, Gredos.

Leech, G. N. (1983): Principles of Pragmatics. London, Longman.

Lewandowski, T. $\left(1995^{4}\right)$ : Diccionario de lingüística. Madrid, Cátedra.

Lucy, J. (1992): Language Diversity and Thought. A Reformulation of the Linguistic Relativity Hypothesis. Cambridge, Cambridge University Press.

Luque Durán, J. d. D. y Manjón Pozas, F. J. (1998): "Fraseología, metáfora y lenguaje taurino”. En Luque Durán, J. de D. y Pamies Beltrán, A. (eds.): Léxico y fraseología. Granada, Método, págs. 43-70.

Lyons, J. (1984): Introducción al lenguaje y a la lingüistica. Barcelona, Teide.

Marco Martínez, C. (1988): "Morfemas clasificadores”, Español Actual, 49, págs. 5-14.

Martín Camacho, J. C. (2003): "Las canciones populares como material de estudio para la etnolingüística. El ejemplo del folklore extremeño", Revista de Estudios Extremeños, 59-3, págs. 993-1016.

Martín Camacho, J. C. (2005): "Lengua, visión del mundo y diacronía". En Actas del Congreso Internacional Análisis del Discurso: Lengua, Cultura, Valores. Madrid, Arco Libros, págs. 2293-2308. 
Martín Vide, C. (1996): "Parámetros para la reflexión sobre el lenguaje humano: a modo de introducción”. En Martín Vide, C. (ed.): Elementos de lingüística. Barcelona, Octaedro, págs. 1-26.

Morant Marco, R. (2005): "Lenguaje y cultura". En López García, Á. y Gallardo, B. (eds.): Conocimiento y lenguaje. Valencia, PUV, págs. 125-154.

Morant Marco, R. y Díaz Rojo, J. A. (2005): "Etnolingüística”. Temarios de Humanidades. Lingüística general, documento on-line de www.liceus.com.

Moreno Cabrera, J. C. (2000): La dignidad e igualdad de las lenguas. Crítica de la discriminación lingüistica. Madrid, Alianza.

Moreno Cabrera, J. C. (2004²): Introducción a la lingüistica. Enfoque tipológico y universalista. Madrid, Síntesis.

Moreno Fernández, F. (1998): Principios de sociolingüística y de sociología del lenguaje. Barcelona, Ariel.

Palmer, G. B. (2000): Lingüistica cultural. Madrid, Alianza.

Pottier, B. (1970): "Le domain de la ethnolinguistique", Languages, 18, págs. 3-11.

Prieto, $\mathrm{M}^{\mathrm{a}}$. (2006): Hablando en plata: de modismos y metáforas culturales. Madrid, Edinumen.

Reus Boyd-Swan, F. (2004): "El léxico taurino en la vida cotidiana", Garoza. Revista de la Sociedad Española de Estudios Literarios de Cultura Popular, 4 (sin paginación).

Robins, R. H. (19954): Lingüistica general. Madrid, Gredos.

Rodríguez Díez, B. (1981): Las lenguas especiales. El léxico del ciclismo. León, Universidad de León.

Rotaetxe Amusategi, K. (1990): "Macrolingüística y microlingüística". Actas del Congreso del XX Aniversario de la SEL. Madrid, Gredos, págs. 1069-1078.

Soler-Espiauba, D. (1990): "Impacto del fenómeno religioso en el español coloquial". En Álvarez Martínez, M $\mathrm{M}^{\mathrm{a}}$ Á. (ed.): Actas del congreso de la Sociedad Española de Lingüística. XX Aniversario. Madrid, Gredos, págs. 769-786.

Tusón, J. (1996): Los prejuicios lingüísticos. Barcelona, Octaedro.

Tusón Valls, A. (1997): Análisis de la conversación. Barcelona, Ariel.

Whorf, B. L. (1941): "La relación entre lenguaje y pensamiento y conducta habituales". En Garvin, P. L. y Lastra de Suárez, Y. (eds.) (1974): Antología de estudios de etnolingüística y sociolingüística. México, UNAM, págs. 125-152.

Wierzbicka, A. (1997): Understanding Cultures through their Key Words: English, Russian, Polish, German, and Japanese. Oxford, Oxford University Press. 